Alma Mater Studiorum - Università di Bologna DEPARTMENT OF ECONOMICS

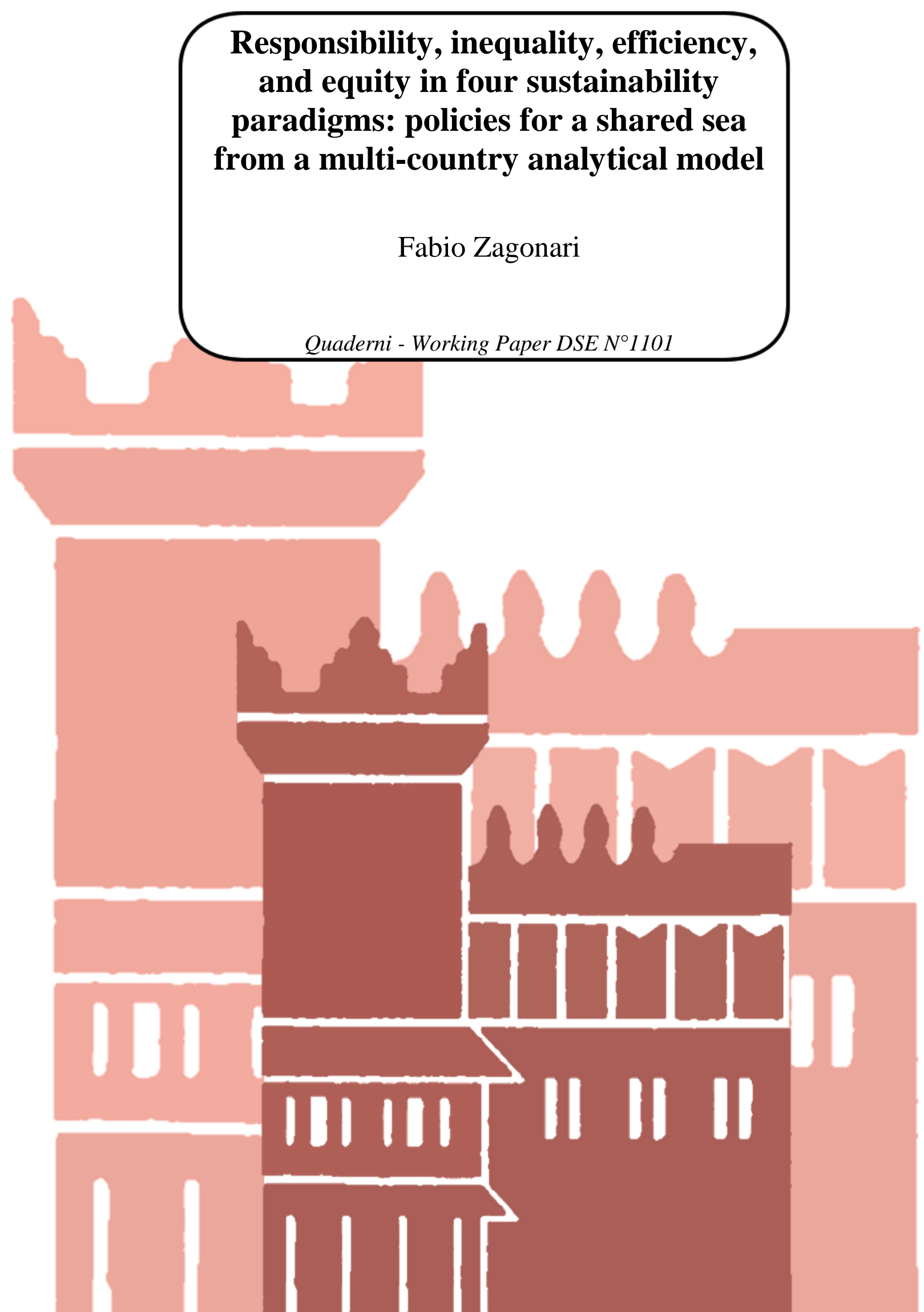




\title{
Responsibility, inequality, efficiency, and equity in four sustainability paradigms: policies for a shared sea from a multi-country analytical model
}

\author{
Fabio Zagonari \\ Dipartimento di Scienze Economiche, Università di Bologna, via Angherà 22, 47900 Rimini (Italy) \\ Phone: 00390541434135 Fax: 00390541434120 Email: fabio.zagonari@ unibo.it
}

\begin{abstract}
This paper develops a theoretical framework for four sustainability paradigms (weak sustainability, a-growth, de-growth, strong sustainability) within cooperative and non-cooperative scenarios, and includes changes in four values (a sense of responsibility to nature and future generations; aversion to inequality for current and future generations). The model assesses the feasibility of sustainability solutions for a shared environment as a function of specific value changes in each country by interpreting these value changes as support for environmental policies. The solutions are defined in terms of consumption, use of the environment, and welfare of representative individuals in each country; they are characterised by efficiency and equality at both intra- and inter-generational levels; they are checked for internal consistency and consistency with alternative approaches such as utilitarianism, egalitarianism (i.e., Arneson, Dworkin, Sen), and contractarianism. Theoretical insights are obtained by comparing contextual stability and relative effectiveness of the environment's use among countries in alternative scenarios. A case study of the Baltic Sea operationally suggests that the currently adopted strong sustainability (i.e., an ecosystem approach) in a non-cooperative scenario (i.e., countries attempt to maximize their own rather than overall welfare) is internally consistent, relatively efficient, and consistent with Dworkin egalitarianism. Agrowth was never feasible, but de-growth in which Denmark, Finland, Germany, and Sweden increase environmental protection would increase intra-generational equality; de-growth or weak sustainability in which Estonia, Latvia, Lithuania, Poland, and Russia increase environmental R\&D would increase intra- and inter-generational equality; weak sustainability and de-growth consistent with Arneson and Dworkin egalitarianism would improve the environmental status.
\end{abstract}

Keywords

Weak sustainability; a-growth; de-growth; strong sustainability; duty; inequality; efficiency; equity

JEL classification

Q5 


\section{Introduction}

Four main sustainability paradigms have been suggested in the literature (Zagonari, 2016): weak sustainability, a-growth, de-growth, and strong sustainability. Note that in this context, the economic general equilibrium framework is similar to weak sustainability, whereas the ecosystem services framework is close to strong sustainability. As well, two main value changes have been evoked to achieve sustainability: a sense of responsibility for nature (Pedersen, 2015; Saniotis, 2012; Van der Werff et al., 2013) or for future generations (Caselles, 2013; Koukouzelis, 2012), and an aversion to inequality with respect to current or future generations (Golub et al., 2013; Kopnina, 2016). Note that improved environmental technology and modified consumption patterns can be considered here as context changes for any combination of paradigms and values.

The purpose of the present study was to develop a model for the four sustainability paradigms within a single framework that accounts for changes in the four values (a sense of responsibility for nature or future generations; aversion to intra- or inter-generational inequality) and that could be used to socially characterise each country that cooperates (or chooses to not cooperate) in managing a shared environment, such as a sea. To support this goal, I develop a model to assess the feasibility of various sustainability solutions for a shared environment that depend on changes in values that could support specific environmental policies in each country. Analytical solutions will be characterised using the consumption level, the direct and indirect use of Earth's resources (hereafter, environment use), and the welfare level for representative individuals in each country by providing both theoretical insights and empirical findings. In particular, analytical solutions will be developed to theoretically compare the stability of each solution in response to changes in context and the relative effectiveness of environment uses in different countries in alternative scenarios. These analytical solutions will be applied to the Baltic Sea as a case study to empirically rank the sustainability solutions in terms of their feasibility, stability, and effectiveness.

Moreover, I will discuss two key efficiency concepts (i.e., Pareto- and Kaldor-Hicks efficiency with respect to welfare) and two key inequality measures (i.e., Gini and MaxMin inequalities with respect to consumption, environment use, and welfare) at both intra- and inter-generational levels. This will empirically reveal the internal consistency of the sustainability paradigms with respect to inequality (e.g., weak sustainability cannot be linked to a large aversion to inequality) and to efficiency (e.g., weak sustainability must be coupled with Kaldor-Hicks efficiency).

Finally, three main equity approaches will be described: a utilitarian approach (i.e., Harsanyi), an egalitarian approach (i.e., Arneson for welfare; Dworkin for consumption or environment use; Sen for consumption and environment use), and a contractarian approach (i.e., Rawls) (Habib, 2013). This will empirically characterize the sustainability solutions in terms of distributive justice.

Note that equality refers to providing the same consumption, environment use, or welfare to all parties, even if that is not a "fair" distribution, whereas equity refers to a "fair" distribution, even if that distribution is not equal.

In other words, from a positive perspective, this study will identify for each sustainability paradigm which value changes are crucial to meet sustainability conditions for a shared environment (here, the Baltic Sea) by turning specific value changes (e.g., a sense of responsibility for nature or future generations) in each country into specific environmental policies (e.g., environmental protection and $R \& D$ ) in each country. I will also determine the internal consistency of each solution and its consistency with various equity approaches by measuring its efficiency in terms of welfare and its effectiveness in terms of environment use.

Note that all insights about the feasibility of a sustainability paradigm for the current generation are based on per capita data for representative individuals in each country, weighted according to the country's proportion of the total population in the study area. Moreover, the responses of sustainability conditions to the main changes in context (i.e., improved technology, modified consumption) are examined (Zagonari, 2015). Finally, a representative individual for all countries from the current generation is compared with one from the future generation to describe intergenerational equity and efficiency. 


\section{Paradigms, concepts, and approaches}

This section concisely defines the four sustainability paradigms, efficiency concepts, and equity approaches identified in section 1.

A sustainability solution is Pareto-efficient if current generations in each country obtain greater welfare than in the status quo situation. In other words, there are no losers. A sustainability solution is Kaldor-Hicks efficient if current generations in all countries combined obtain greater welfare than in the status quo situation so that the losers can potentially receive compensation from the winners. A sustainability solution reduces inequalities between current generations in terms of consumption, environment use, or welfare level if the Gini index for one or more of these variables is smaller than the Gini index for the same variable in the status quo situation; it is then defined as Gini-equitable. A sustainability solution improves the conditions for the least advantaged current generation in terms of consumption, environment use, or welfare if the minimum value of one or more variables is larger than its value in the status quo situation; it is then defined as MaxMinequitable.

The main assumptions behind weak sustainability (i.e., development that meets the needs of the present generation without compromising the ability of future generations to meet their own needs) can be summarized as follows (Schlör et al., 2015): needs are used as the unit of measurement; the same weights are used for current and future generations; and there is unconditional substitution among current economic, social, and environmental forms of capital at both intra- and intergenerational levels. A sustainability solution is consistent with weak sustainability if it is at least Kaldor-Hicks efficient, and if it assumes small aversion to inter- and intra-generational inequality. A-growth is an ecological and economic strategy focused on indifference to or neutrality about the economic level and growth, which are considered non-robust and unreliable indicators of social welfare and progress (Van den Bergh, 2010, 2011). It can be characterised as follows: welfare is used as the unit of measurement, as deduced from the aim of moving from wrong prices that result from the many neglected non-market transactions (e.g., informal activities and relationships) and the many unpriced environmental effects to right prices (i.e., prices that account for both nonmarket and unpriced values); different weights are used for current and future generations; and substitution between forms of capital is possible. A sustainability solution is consistent with agrowth if it is Gini-equitable for welfare, and if it assumes a small aversion to inter-generational and intra-generational inequality.

De-growth is an ecological and economic perspective based on achieving a socially sustainable and equitable reduction (and eventually stabilization) of the quantity of materials and energy that a society extracts, processes, transports, distributes, consumes, and returns to the environment as wastes (Kallis, 2011; Kallis et al., 2012). It can be characterised as follows: happiness is the unit of measurement, with a priority on meeting the needs of the poorest individuals, as deduced from the aim of introducing a basic income; the same weight is assigned to current and future generations; and substitution among forms of capital is acceptable. A sustainability solution is consistent with a de-growth paradigm if it is MaxMin-equitable for welfare and if it assumes a large aversion to interand intra-generational inequality.

The main assumptions behind strong sustainability (i.e., a development that allows future generations to access the same amount of natural resources and the same environmental status as the current generation) can be summarized as follows (Jain \& Jain, 2013): requirements for some incommensurable categories as the unit of measurement; possibly assignment of different weights to current and future generations; and no substitution between current or future forms of capital, with natural and physical or social capital considered to be complementary. A sustainability solution is consistent with strong sustainability if it is Gini-equitable for consumption and environment use, and if it assumes a large aversion to inter- and intra-generational inequality.

Utilitarianism, in the version considered here (Harsanyi, 1982), can be characterised as follows: equally weighting everyone's welfare, with welfare defined as the satisfaction of rational, wellinformed, and self-interested preferences, by maximising the total social welfare. A sustainability 
solution is consistent with the utilitarian approach if it is Pareto-efficient or Kaldor-Hicks efficient and if it assumes a small aversion to inter- and intra-generational inequality.

Egalitarianism, in the main three alternative versions that I focus on here, can be summarised as follows: it involves (1) levelling of resources or primary goods, as in Dworkin (1981); (2) equalising capabilities, as in Sen (1993); or (3) equalising opportunities for welfare, as in Arneson (1989). A sustainability solution is consistent with these egalitarian approaches if it assumes a large aversion to inter- and intra-generational inequality, and if it is Gini-equitable in consumption or environment for case 1, Gini equitable in consumption and environment for case 2, and Giniequitable in welfare for case 3.

Contractarianism, in the version considered here (Rawls, 1971), can be characterised as follows: it arranges social and economic inequalities to the greatest benefit of the least advantaged people by opening offices and positions to everybody. A sustainability solution is consistent with the contractarian approach if it is MaxMin-equitable for consumption, environment, or welfare, and if it assumes a large aversion to inter- and intra-generational inequality.

Note that my analysis disregards libertarian approaches, both in terms of positive rights (Lomasky, 1987) and negative rights (Nozick, 1974), because it is arguable whether future generations or nature have rights in this context (Gosseries, 2008). Next, equality is assumed to be instrumental (Kershnar \& Purves, 2016), since a value is attached to the consequences for people.

\section{The model}

This section provides simple formalisations for the four sustainability paradigms identified in Section 2, with the goal of requiring as little data as possible about representative individuals in each country. See Appendix A for a list of all abbreviations used in the model.

Let us assume that $E_{i}$ identifies the per capita use of the shared environment by the current generation in country $i$. The per capita equilibrium level consistent with the current relevant population is $\eta$. Let us assume that $X_{i}$ identifies the per capita consumption of the current generation in country $i$. Thus, the use of the environment for the current generation in country $i$ is given by $E_{i}=$ $\theta_{i} X_{i}$, and for the future generation is given by $E_{\mathrm{F}}=\theta_{\mathrm{F}} X F$, where $\theta_{i}$ and $\theta_{\mathrm{F}}$ represent the use of the environment for each consumption unit for the current generation in country $i$ and for the future generation, respectively: $\theta_{i}$ will be set at current values based on the current technology, and then simulated as smaller than current values to analyse the impacts of a technological improvement, whereas $\theta_{\mathrm{F}}$ is assumed to be the average of $\theta_{i}$ across all countries:

$$
X F=\eta / \theta_{\mathrm{F}} \text { with } \theta_{\mathrm{F}}=\frac{1}{n} \sum_{i}^{n} \theta_{i}
$$

Two main sustainability conditions can be formalised. The weighted sustainability condition requires that use of the shared environment be weighted according to the proportions of the total population in the relevant countries $\left(p_{i}\right): E C=\sum p_{i} E_{i}$, where $E C$ stands for the total weighted use of the shared environment by the current generation. The non-weighted sustainability condition requires that use of the shared environment be averaged between the representative individuals in each country: $E C=(1 / n) \sum E_{i}$. Thus, in terms of consumption levels, these sustainability conditions become, respectively: $\eta=E C=\sum p_{i} \theta_{i} X_{i}$ and $\eta=E C=(1 / n) \sum \theta_{i} X_{i}$. I will use the non-weighted sustainability condition for strong sustainability, and the weighted sustainability condition for the other sustainability paradigms. Let us assume that the utility for the future generation $(U F)$ depends only on the consumption level:

$$
U F=X F^{\alpha \mathrm{F}} \text { with } \alpha_{\mathrm{F}}=\frac{1}{n} \sum_{i}^{n} \alpha_{i}
$$

Where $\alpha_{F}$ represents the future preference for consumption, and it is assumed to be the average across all countries of the current preference for consumption, $\alpha_{i}$. Indeed, I assume that use of the environment is in a long-run equilibrium so that people do not need to feel a duty to preserve the environment for subsequent generations. Let us assume that the welfare of the current generation in 
country $i\left(U_{i}\right)$ depends on the consumption level, the current use of the shared environment, and the welfare of the future generation:

$$
U_{i}=X_{i}^{\alpha i}\left(\sum p_{i} E_{i}\right)^{-\beta i} U F^{\gamma i}
$$

Where $\alpha_{i}$ represents the current preference for consumption in country $i, \beta_{i}$ represents the degree of concern for nature, and $\gamma_{i}$ represents the degree of concern for future generations. In other words, each country is assumed to be concerned about the shared environment (i.e., $E C$ ) rather than about its own environment (i.e., $E_{i}$ ). This could account for a country $i$ characterised by an above-average concern for the environment suffering from an above-average use of the environment by country $j$. Next, each country is assumed to disregard the welfare of the current generation in other countries (Lauwers, 2012). Indeed, the concern for welfare in other countries seems to be more plausible in the case of different levels of development (e.g., European vs. African countries that are facing the Mediterranean Sea). Appendix B presents a formalisation of this analysis for countries with different developmental levels.

Note that a logarithmic transformation of the Cobb-Douglas utility functions permits analytical solutions. Moreover, apart from nature, welfare could be directly affected by other types of capital such as social, physical, and human capital, where these forms of capital, like nature, contribute to achieving a given consumption level. Finally, each parameter attached to an item of the CobbDouglas utility function (e.g., $\alpha$ to consumption, $\beta$ to the environment, $\gamma$ to the welfare of future generations) can be related to the proportion of the budget spent to purchase it. Let us assume that a representative individual in the current generation is concerned about welfare inequality between countries:

$$
U C=\left[\left(\sum p_{i} U_{i}\right)^{1-\varepsilon}\right]^{1 /(1-\varepsilon)}
$$

Where $\varepsilon$ is the degree of aversion to intra-generational inequality (Asheim et al., 2012). Thus, the overall utility is given by:

$$
U=\left[U C^{1-\zeta}+U F^{1-\zeta}\right]^{1 /(1-\zeta)}
$$

Where $\zeta$ is the degree of aversion to inter-generational inequality. Alternatively, a representative individual in the current generation could be concerned about inequality in use of the shared environment between countries:

Thus, the overall welfare would be given by:

$$
W C=\left[\sum E_{i}{ }^{1-\varepsilon}\right]^{1 /(1-\varepsilon)}
$$

$$
W=\left[E C^{1-\zeta}+E F^{1-\zeta}\right]^{1 /(1-\zeta)}
$$

Note that the time discount rate is assumed to be 0 , as this is the only value that is consistent with long-run equilibria. Moreover, each social utility or welfare function can be linked to an Atkinson inequality index, in which parameters $\varepsilon$ and $\zeta$ also represent inequality aversion (Cowell, 1995). Finally, extreme values of $\varepsilon$ and $\zeta$ (i.e., at 0 and 1) permit analytical solutions.

Many theoretical definitions of the four sustainability paradigms can be suggested (Aznar-Marquez \& Ruiz-Tamarit, 2016). Here, I will apply the analytical definitions summarised in Table 1.

Note that countries could adopt a non-cooperative attitude (here, represented by a Nash equilibrium for each country's welfare; this represents a scenario in which one or more countries attempt to maximize their own welfare rather than overall welfare) or a cooperative attitude (here, represented by maximisation of the overall welfare or utility). Moreover, referring to a non-cooperative scenario disregards the aversion to intra- and inter-generational inequality: a country that maximises its own welfare by taking choices by other countries as given neglects the consequences of its choices for the welfare of other countries, and, consequently, neglects the differences between its current welfare and other countries' current welfare as well as the differences between all countries' current welfare and all countries' future welfare. Finally, replacing $E C \leq E F$ with $E_{i} \leq E F$ for each $i$ (i.e., 
each country is expected to achieve its own sustainability) is inappropriate in the case of a shared environment.

Table 1. The analytical definitions of the four sustainability paradigms. $U$, overall utility in terms of consumption; $U F$, utility for the future generation; $U_{i}$, utility for the current generation in country $i ; U C$, total weighted utility for the current generation; $E C$, total weighted use of the environment by the current generation; $E F$, use of the environment by the future generation; $X C$, total weighted per capita consumption by the current generation; $X F$, per capita consumption by the future generation; $W$, overall welfare in terms of the environment.

\begin{tabular}{|c|c|c|}
\hline Paradigm & Non-cooperative scenario & Cooperative scenario \\
\hline Weak sustainability & $\operatorname{Max} U_{\mathrm{i}}$ s.t. $U F \geq U_{\mathrm{i}}$ & $\operatorname{Max} U$ s.t. $U F \geq U C$ \\
\hline A-growth & $\operatorname{Max} U_{\mathrm{i}}$ s.t. $E C \leq E F$ & $\operatorname{Max} U$ s.t. $E C \leq E F$ \\
\hline De-growth & $\operatorname{Min} X C$ s.t. $U F \geq U_{\mathrm{i}}$ & $\operatorname{Min} X C$ s.t. $U F \geq U C$ \\
\hline Strong sustainability & $\operatorname{Max} W$ s.t. $E C \leq E F$ & $\operatorname{Max} W$ s.t. $E C \leq E F$ \\
\hline
\end{tabular}

Note that the analytical definition of de-growth does not depend on $E_{i}$. This is consistent with the main critiques to this paradigm (i.e., a reduction in the economic scale might not lead to a reduction in environment use). Moreover, the four sustainability paradigms share couples of conditions: for example, Max $U_{i}$ and Max $U$ are shared by weak sustainability and a-growth; $U F \geq U C$ is shared by weak sustainability and de-growth; and $E C \leq E F$ is shared by a-growth and strong sustainability. Finally, the analytical definition of strong sustainability assumes that $\varepsilon$ and $\zeta$ are set at 1 . This is consistent with the main feature of this paradigm (i.e., maximum aversion to inequality).

These systems of equations will be solved for $X_{i}$ to check for the existence of sustainability solutions at current preferences or for a set of consumption preferences (i.e., $\alpha_{i}, \beta_{i}, \gamma_{i}, \varepsilon, \zeta$ ) at current consumption levels to check which country should change its preferences to a larger extent. Moreover, because other changes could affect the equilibria, I will perform a ceteris paribus analysis. Finally, dynamic stability conditions will not be considered; instead, static sustainability equilibria will be obtained.

\section{Analytical results}

This section will provide analytical solutions in the case of extreme values of the parameters, whereas section 5 will provide numerical solutions for a case study for countries surrounding the Baltic Sea. Note that, for the sake of completeness, solutions for each paradigm will be replicated, although they are equal in some different situations (e.g., strong sustainability is not affected by a cooperative vs. non-cooperative context, and it does not depend on $\beta_{i}$ nor on $\gamma_{i}$ ).

\subsection{Solutions in a non-cooperative scenario $(\beta, y)$}

For a situation in which each country chooses its own consumption level $X_{i}$ to maximise its own utility $U_{i}$ by taking as given the consumption levels in other countries $X_{j}$ (i.e., a Nash equilibrium) so that the current generation's aversion to inequality for the current generation and for future generations are both at their minimum (i.e., $\varepsilon=\zeta=0$ ), the analytical solutions for the four sustainability paradigms are as follows:

Weak sustainability (i.e., first-order conditions for $\operatorname{Max} U_{i}$ and $U F \geq U_{i}$ ):

$$
\text { (I) } X_{i}=\frac{\eta \alpha_{i}}{p_{i} \theta_{i} \beta_{i}} \text { and (II) } X_{i} \leq E C^{\beta i / \alpha_{i}} U F^{(1-\gamma i) / \alpha_{i}}
$$

A-growth (i.e., first-order conditions for $\operatorname{Max} U_{i}$ and $E C \leq E F$ ):

De-growth (i.e., $U F \geq U_{i}$ and $X F \leq X C$ ):

$$
\text { (I) } X_{i}=\frac{\eta \alpha_{i}}{p_{i} \theta_{i} \beta_{i}} \text { and (II) } \sum_{i}^{n} p_{i} \theta_{i} X_{i} \leq \eta
$$

$$
\text { (I) } X_{i} \leq\left(E C^{\beta i} U F^{1-\gamma \mathrm{i}}\right)^{1 / \alpha_{i}} \text { and (II) } \sum_{i}^{n} p_{i} X_{i} \geq X F
$$

Strong sustainability (i.e., first-order conditions for Max $W$ and $E C \leq E F$ ): 


$$
\text { (I) } X_{i}=\frac{\eta}{\theta_{i}} \text { and (II) } \sum_{i}^{n} p_{i} \theta_{i} X_{i} \leq \eta
$$

\subsection{Solutions in cooperative scenarios $(\beta, Y, \varepsilon, \zeta)$}

For a situation in which all countries simultaneously choose each current consumption level $X_{i}$ to maximise the overall utility $U$ (i.e., a cooperative equilibrium), the current generation's aversion to inequality for the current generation and for future generations are both at their minimum (i.e., $\varepsilon=\zeta$ $=0$ ), the analytical solutions for the four sustainability paradigms are as follows:

Weak sustainability (i.e., first-order conditions for Max $U$ and $U F \geq U C$ ):

where:

$$
\text { (I) } X_{i}=\frac{\eta \alpha_{i}}{\theta_{i} \sum_{i}^{n} p_{i} \beta_{i}} \text { and (II) } X_{i} \leq\left[\left(U F C_{i}\right) / p_{i}\right]^{1 / \alpha_{i}}
$$

$$
U F C_{i}=\left(E C^{\beta i} U F^{1-\gamma \mathrm{i}}-\sum_{k}^{n} p_{j} X_{j}^{\alpha j} E C^{\beta i-\beta j} U F^{\gamma j-\gamma i}\right)
$$

A-growth (i.e., first-order conditions for Max $U$ and $E C \leq E F$ ):

De-growth (i.e., $U F \geq U C$ and $X F \leq X C$ ):

$$
\text { (I) } X_{i}=\frac{\eta \alpha_{i}}{\theta_{i} \sum_{i}^{n} p_{i} \beta_{i}} \text { and (II) } \sum_{i}^{n} p_{i} \theta_{i} X_{i} \leq \eta
$$

$$
\text { (I) } X_{i} \leq\left[\left(U F C_{i}\right) / p_{i}\right]^{1 / \alpha_{i}} \text { and (II) } \sum_{i}^{n} p_{i} X_{i} \geq X F
$$

Strong sustainability (i.e., first-order conditions for Max $W$ and $E C \leq E F$ ):

$$
\text { (I) } X_{i}=\frac{\eta}{\theta_{i}} \text { and (II) } \sum_{i}^{n} p_{i} \theta_{i} X_{i} \leq \eta
$$

For a situation in which all countries simultaneously choose each consumption level $X_{i}$ to maximise the overall utility $U$ (i.e., a cooperative equilibrium), with the current generation's aversion to inequality for the current generation at its maximum (i.e., $\varepsilon=1$ ), and with the current generation's aversion to inequality for future generations at its minimum (i.e., $\zeta=0$ ), the analytical solutions for the four sustainability paradigms are as follows:

Weak sustainability (i.e., first-order conditions for Max $U$ and $U F \geq U C$ ):

$$
\text { (I) } X_{i}=\eta \frac{p_{i} \beta_{i}-p_{j} \beta_{j}}{p_{i} \alpha_{i}} U F^{-\frac{p_{i} \gamma_{i}-p_{j} \gamma_{j}}{p_{i} \alpha_{i}}} X_{j}^{\frac{p_{j} \alpha_{j}}{p_{i} \alpha_{i}}} \text { and (II) } X_{i} \leq\left[\left(U F C_{i}\right) / p_{i}\right]^{1 / \alpha_{i}}
$$

A-growth (i.e., first-order conditions for $\operatorname{Max} U$ and $E C \leq E F$ ):

$$
\text { (I) } X_{i}=\eta^{\frac{p_{i} \beta_{i}-p_{j} \beta_{j}}{p_{i} \alpha_{i}}} U F^{-\frac{p_{i} \gamma_{i}-p_{j} \gamma_{j}}{p_{i} \alpha_{i}}} X_{j}^{\frac{p_{j} \alpha_{j}}{p_{i} \alpha_{i}}} \text { and (II) } \sum_{i}^{n} p_{i} \theta_{i} X_{i} \leq \eta
$$

De-growth (i.e., $U F \geq U C$ and $X F \leq X C$ ):

$$
\text { (I) } X_{i} \leq\left[\left(U F C_{i}\right) / p_{i}\right]^{1 / \alpha_{i}} \text { and (II) } \sum_{i}^{n} p_{i} X_{i} \geq X F
$$

Strong sustainability (i.e., first-order conditions for Max $W$ and $E C \leq E F$ ):

$$
\text { (I) } X_{i}=\frac{\eta}{\theta_{i}} \text { and (II) } \sum_{i}^{n} p_{i} \theta_{i} X_{i} \leq \eta
$$

For a situation in which all countries simultaneously choose each consumption level $X_{i}$ to maximise the overall utility $U$ (i.e., a cooperative equilibrium), with the current generation's aversion to inequality for the current generation at its minimum (i.e., $\varepsilon=0$ ), and with the current generation's aversion to inequality for future generations at its maximum (i.e., $\zeta=1$ ), the analytical solutions for the four sustainability paradigms are as follows:

Weak sustainability (i.e., first-order conditions for Max $U$ and $U F \geq U C$ ):

$$
\text { (I) } X_{i}=\exp ^{\frac{U F}{p_{i} \alpha_{i}}} \eta^{\frac{\sum_{i}^{n} p_{i} \beta_{i}}{p_{i} \alpha_{i}}} U F^{-\frac{\sum_{i}^{n} p_{i} \gamma_{i}}{p_{i} \alpha_{i}}} \prod_{k}^{n} X_{j}^{-\frac{p_{j} \alpha_{j}}{p_{i} \alpha_{i}}} \text { and (II) } X_{i} \leq\left[\left(U F C_{i}\right) / p_{i}\right]^{1 / \alpha_{i}}
$$

A-growth (i.e., first-order conditions for Max $U$ and $E C \leq E F$ ): 


$$
\text { (I) } X_{i}=\exp ^{\frac{U F}{p_{i} \alpha_{i}}} \eta^{\frac{\sum_{i}^{n} p_{i} \beta_{i}}{p_{i} \alpha_{i}}} U F^{-\frac{\sum_{i}^{n} p_{i} \gamma_{i}}{p_{i} \alpha_{i}}} \prod_{k}^{n} X_{j}^{-\frac{p_{j} \alpha_{j}}{p_{i} \alpha_{i}}} \text { and (II) } \sum_{i}^{n} p_{i} \theta_{i} X_{i} \leq \eta
$$

De-growth (i.e., $U F \geq U C$ and $X F \leq X C$ ):

$$
\text { (I) } X_{i} \leq\left[\left(U F C_{i}\right) / p_{i}\right]^{1 / \alpha_{i}} \text { and (II) } \sum_{i}^{n} p_{i} X_{i} \geq X F
$$

Strong sustainability (i.e., first-order conditions for Max $W$ and $E C \leq E F$ ):

$$
\text { (I) } X_{i}=\frac{\eta}{\theta_{i}} \text { and (II) } \sum_{i}^{n} p_{i} \theta_{i} X_{i} \leq \eta
$$

Where $i$ refers to a sum or a product that includes all $n$ countries, whereas $k$ refers to a sum that excludes country $i$.

Comparing solutions in the non-cooperative and cooperative scenarios with $\varepsilon=\zeta=0$ for weak sustainability and a-growth suggests that each country must consume less in a cooperative scenario than in a non-cooperative scenario (i.e., $p_{i} \beta_{i}<\sum p_{i} \beta_{i}$ ), although this decrease must be smaller if the country is characterised by an above-average concern for the environment (i.e., $\beta_{i}>\sum p_{i} \beta_{i}$ ).

Analysing solutions in cooperative scenarios with $\varepsilon=1$ and $\zeta=0$ for weak sustainability and agrowth highlights that, regardless of the environmental use intensity, a larger country $i$ characterised by a larger preference for consumption (i.e., $p_{i} \alpha_{i}>p_{j} \alpha_{j}$ ), a smaller concern for the environment (i.e., $p_{i} \beta_{i}<p_{j} \beta_{j}$ ), and a larger concern for future generations (i.e., $p_{i} \gamma_{i}>p_{j} \gamma_{j}$ ) than country $j$ must consume less than country $j$.

Analysing solutions for cooperative scenarios with $\varepsilon=0$ and $\zeta=1$ for weak sustainability and agrowth highlights that, regardless of environmental use intensity, a larger country $i$ characterised by a larger preference for consumption than the other countries (i.e., $p_{i} \alpha_{i}>p_{j} \alpha_{j}$ ) must consume less than the other countries, whereas the concerns for the environment $\left(\beta_{i}\right)$ and for future generations $\left(\gamma_{i}\right)$ affect sustainable consumption in country $i$ based on the average for all countries rather than on the different values for country $i$ and country $j$.

Comparing solutions in non-cooperative and cooperative scenarios for de-growth suggests that, regardless of environmental use intensity, a country $i$ characterised by a larger concern for the environment (i.e., $\beta_{i}>\beta_{j}$ for all $j \neq i$ ) and a smaller concern for future generations (i.e., $\gamma_{i}<\gamma_{j}$ for all $j \neq i$ ) than all other countries must consume less in a cooperative scenario than in a non-cooperative scenario.

\subsection{Contextual stability from sensitivity analyses $(\alpha, \theta)$}

Since $X_{i}$ directly affects both utility $U_{i}$ and environment use $E_{i}$, this section will calculate the partial derivatives of $X_{i}$ with respect to the contextual parameters (i.e., $\alpha_{i}$ and $\theta_{i}$ ) to clarify the magnitude of their effects (i.e., the resulting rate of change). Note that if the sustainability solution is identified by an equality and an inequality (e.g., weak sustainability and a-growth), I will show the partial derivative of the equality; the partial derivative of the inequality affects only the feasibility of the solution. Moreover, strong sustainability conditions do not depend on $\alpha_{i}$ and depend quadratically on $\theta_{i}$ (i.e., $\partial X_{i} / \partial \theta_{i}=-\eta / \theta_{i}{ }^{2}$ ). Finally, if the sustainability solution is identified by two weak inequalities (e.g., de-growth), I will calculate the partial derivatives of both inequalities as if they were equalities; both these equalities affect the sustainability solutions.

In particular, in a non-cooperative scenario for weak sustainability and a-growth:

$$
\frac{\partial X_{i}}{\partial \alpha_{i}}=\frac{\eta}{p_{i} \theta_{i} \beta_{i}} \text { and } \frac{\partial X_{i}}{\partial \theta_{i}}=-\frac{\eta \alpha_{i}}{\theta_{i}^{2} p_{i} \beta_{i}}
$$

In a cooperative scenario with $\varepsilon=0$ and $\zeta=0$ for weak sustainability and a-growth:

$$
\frac{\partial X_{i}}{\partial \alpha_{i}}=\frac{\eta}{\theta_{i} \sum_{i}^{n} p_{i} \beta_{i}} \text { and } \frac{\partial X_{i}}{\partial \theta_{i}}=-\frac{\eta \alpha_{i}}{\theta_{i}^{2} \sum_{i}^{n} p_{i} \beta_{i}}
$$

In a cooperative scenario with $\varepsilon=1$ and $\zeta=0$ for weak sustainability and a-growth: 


$$
\begin{aligned}
& \frac{\partial X_{i}}{\partial \alpha_{i}}=\eta^{\frac{p_{i} \beta_{i}-p_{j} \beta_{j}}{p_{i} \alpha_{i}}} U F^{-\frac{p_{i} \gamma_{i}-p_{j} \gamma_{j}}{p_{i} \alpha_{i}}} \alpha_{i} X_{j}^{\frac{p_{j} \alpha_{j}}{p_{i} \alpha_{i}}}\left[\frac{p_{i} \gamma_{i}-p_{j} \gamma_{j}}{p_{i} \alpha_{i}} \ln [U F]-\frac{p_{i} \beta_{i}-p_{j} \beta_{j}}{p_{i} \alpha_{i}} \ln [\eta]\right. \\
& \left.-\frac{p_{j} \alpha_{j}}{p_{i} \alpha_{i}} \ln \left[X_{i}\right]\right] \text { and } \frac{\partial X_{i}}{\partial \theta_{i}}=0
\end{aligned}
$$

In a cooperative scenario with $\varepsilon=0$ and $\zeta=1$ for weak sustainability and a-growth:

$$
\begin{aligned}
\frac{\partial X_{i}}{\partial \alpha_{i}}=\frac{1}{\alpha_{i}^{2} p_{i}}\left\{\operatorname { e x p } ^ { \frac { U F } { p _ { i } \alpha _ { i } } } \eta ^ { \frac { \sum _ { i } ^ { n } p _ { i } \beta _ { i } } { p _ { i } \alpha _ { i } } } U F ^ { - \frac { \sum _ { i } ^ { n } p _ { i } \gamma _ { i } } { p _ { i } \alpha _ { i } } } \prod _ { k } ^ { n } X _ { j } ^ { - \frac { p _ { j } \alpha _ { j } } { p _ { i } \alpha _ { i } } } \left[\sum_{i}^{n} p_{i} \gamma_{i} \ln [U F]-\sum_{i}^{n} p_{i} \beta_{i} \ln [\eta]\right.\right. \\
\left.\left.+p_{j} \alpha_{j} \ln \left[X_{i}\right]\right]-U F\right\} \text { and } \frac{\partial X_{i}}{\partial \theta_{i}}=0
\end{aligned}
$$

In a non-cooperative scenario for de-growth:

$$
\frac{\partial X_{i}}{\partial \alpha_{i}}=-\frac{\left(E C^{\beta i} U F^{1-\gamma \mathrm{i}}\right)^{1 / \alpha_{i}} \ln \left[E C^{\beta i} U F^{1-\gamma i}\right]}{\alpha_{i}{ }^{2}} \text { or } \frac{\partial X_{i}}{\partial \theta_{i}}=-\frac{n \eta}{\left(\sum_{i}^{n} \theta_{i}\right)^{2}}
$$

In a cooperative scenario for de-growth:

$$
\frac{\partial X_{i}}{\partial \alpha_{i}}=-\frac{\left[\left(U F C_{i}\right) / p_{i}\right]^{1 / \alpha_{i}} \ln \left[E C^{\beta i} U F^{1-\gamma \mathrm{i}}-\sum_{j}^{n} p_{j} X_{j}^{\alpha i} E C^{\beta i-\beta j} U F^{\gamma j-\gamma i}\right]}{\alpha_{i}{ }^{2}} \text { or } \frac{\partial X_{i}}{\partial \theta_{i}}=-\frac{n \eta}{p_{i}\left(\sum_{i}^{n} \theta_{i}\right)^{2}}
$$

Where $i$ refers to a sum or a product that includes all $n$ countries, whereas $k$ refers to a sum that excludes country $i$.

Comparing the derivatives in non-cooperative and cooperative scenarios with $\varepsilon=\zeta=0$ for weak sustainability and a-growth suggests that each country changes its consumption less in a cooperative scenario than in a non-cooperative scenario (i.e., $p_{i} \beta_{i}<\sum p_{i} \beta_{i}$ ) due to improved environmental technology and modified consumption patterns, although this decrease must be smaller if the country is characterised by an above-average concern for the environment (i.e., $\beta_{i}>\sum p_{i} \beta_{i}$ ).

Analysing the derivatives in a cooperative scenario with $\varepsilon=1$ and $\zeta=0$ for weak sustainability and a-growth highlights that a larger country $i$ characterised by a larger preference for consumption (i.e., $p_{i} \alpha_{i}>p_{j} \alpha_{j}$ ), a smaller concern for the environment (i.e., $p_{i} \beta_{i}<p_{j} \beta_{j}$ ), and a larger concern for future generations (i.e., $p_{i} \gamma_{i}>p_{j} \gamma_{j}$ ) than country $j$ changes its consumption to a larger extent than the other country $j$ due to modified consumption patterns.

Analysing the derivatives in a cooperative scenario with $\varepsilon=0$ and $\zeta=1$ for weak sustainability and a-growth highlights that a larger country $i$ characterised by a larger preference for consumption than the other countries (i.e., i.e., $p_{i} \alpha_{i}>p_{j} \alpha_{j}$ ) changes its consumption to a smaller extent than the other countries due to modified consumption patterns, whereas the concerns for the environment $\left(\beta_{i}\right)$ and for future generations $\left(\gamma_{i}\right)$ affect sustainable consumption in country $i$ based on the average for all countries rather than on the different values for country $i$ and country $j$.

Comparing the derivatives in non-cooperative and cooperative scenarios for de-growth suggests that a country $i$ characterised by a larger concern for the environment (i.e., $\beta_{i}>\beta_{j}$ for all $j \neq i$ ) and a smaller concern for future generations (i.e., $\gamma_{i}<\gamma_{j}$ for all $j \neq i$ ) than all other countries changes its consumption to a smaller extent in a cooperative scenario than in a non-cooperative scenario due to improved environmental technology and modified consumption patterns.

\subsection{Relative effectiveness based on a comparison of solutions}

Since strong sustainability attaches a larger relative importance to ecological systems vs. economic systems than in the other sustainability paradigms (i.e., a tentative ordering would be strong sustainability $>$ de-growth $>$ a-growth $>$ weak sustainability), this section will compare consumption levels $X_{i}$ under weak sustainability, a-growth, and de-growth with the consumption level under strong sustainability. In particular, in a non-cooperative scenario, $X_{i}$ for weak sustainability and a-growth is larger than $X_{i}$ for strong sustainability if:

$$
\alpha_{i} \geq p_{i} \beta_{i}
$$

In a cooperative scenario, $X_{i}$ with $\varepsilon=\zeta=0$ for weak sustainability and a-growth is larger than $X_{i}$ for strong sustainability if: 


$$
\alpha_{i} \geq \sum_{i}^{n} p_{i} \beta_{i}
$$

In a cooperative scenario, $X_{i}$ with $\varepsilon=1$ and $\zeta=0$ for weak sustainability and a-growth is larger than $X_{i}$ for strong sustainability if:

$$
\alpha_{i} \geq \frac{\ln [\eta]\left(p_{i} \beta_{i}-p_{j} \beta_{j}\right)-\ln [U F]\left(p_{i} \gamma_{i}-p_{j} \gamma_{j}\right)+\ln \left[X_{j}\right] p_{j} \alpha_{j}}{p_{i} \ln \left[\eta / \theta_{i}\right]}
$$

In a cooperative scenario, $X_{i}$ with $\varepsilon=0$ and $\zeta=1$ for weak sustainability and a-growth is larger than $X_{i}$ for strong sustainability if:

$$
\alpha_{i} \geq \frac{U F+\ln [\eta] \sum_{i}^{n} p_{i} \beta_{i}-\ln [U F] \sum_{i}^{n} p_{i} \gamma_{i}-\sum_{k}^{n} p_{j} \alpha_{j} X_{j}}{p_{i} \ln \left[\eta / \theta_{i}\right]}
$$

In a non-cooperative scenario, $X_{i}$ for de-growth is larger than $X_{i}$ for strong sustainability if:

$$
\alpha_{i} \geq \frac{\ln \left[E C^{\beta i} U F^{1-\gamma i}\right]}{\ln \left[\eta / \theta_{\mathrm{i}}\right]}
$$

In a cooperative scenario, $X_{i}$ for de-growth is larger than $X_{i}$ for strong sustainability if:

$$
\alpha_{i} \geq \frac{\ln \left[E C^{\beta i} U F^{1-\gamma i}-\sum_{k}^{n} p_{j} X_{j}^{\alpha i} E C^{\beta i-\beta j} U F^{\gamma j-\gamma i}\right]}{\ln \left[\eta / \theta_{i}\right]}
$$

Where $i$ refers to a sum that includes all $n$ countries, whereas $k$ refers to a sum that excludes country $i$.

Comparing solutions in non-cooperative and cooperative scenarios with $\varepsilon=\zeta=0$ for weak sustainability and a-growth suggests that, regardless of $\theta_{i}$, each country is likely to consume more than under a strong sustainability solution in non-cooperative scenario than in a cooperative scenario (i.e., $p_{i} \beta_{i}<\sum p_{i} \beta_{i}$ ), but to a smaller extent if the country is characterised by an aboveaverage concern for the environment (i.e., $\beta_{i}>\sum p_{i} \beta_{i}$ ).

Analysing solutions in a cooperative scenario with $\varepsilon=1$ and $\zeta=0$ for weak sustainability and agrowth highlights that each country $i$ in a group of similar countries is likely to consume more than under a strong sustainability solution, although a larger country $i$ characterised by a smaller preference for consumption (i.e., $p_{i} \alpha_{i}<p_{j} \alpha_{j}$ ), by a larger concern for the environment (i.e., $p_{i} \beta_{i}>p_{j}$ $\beta_{j}$ ), and by a smaller concern for future generations (i.e., $p_{i} \gamma_{i}<p_{j} \gamma_{j}$ ) than country $j$ consumes more than under a strong sustainability solution, but to a smaller extent than for the other country $j$.

Analysing solutions in a cooperative scenario with $\varepsilon=0$ and $\zeta=1$ for weak sustainability and agrowth highlights that a larger country $i$ characterised by a larger preference for consumption than the other countries (i.e., $p_{i} \alpha_{i}>p_{j} \alpha_{j}$ ) is likely to consume more than under a strong sustainability solution, and to a larger extent than the other countries, whereas the concerns for the environment $\left(\beta_{i}\right)$ and for future generations $\left(\gamma_{i}\right)$ affect the optimal consumption in the country $i$ based on the average for all countries rather than on the different values for country $i$ and country $j$.

Comparing solutions in non-cooperative and cooperative scenarios for de-growth suggests that, regardless of $\theta_{i}$, a country $i$ characterised by a larger concern for the environment (i.e., $\beta_{i}>\beta_{j}$ for all $j \neq i$ ) and a smaller concern for future generations (i.e., $\gamma_{i}<\gamma_{j}$ for all $j \neq i$ ) than all other countries is likely to consume more than in a strong sustainability solution, but to a larger extent in a cooperative scenario than in a non-cooperative scenario.

\section{Numerical results for a case study of the Baltic Sea}

The Helsinki Commission (HELCOM) was established in 1974 by nine contracting countries (Denmark, Estonia, Finland, Germany, Latvia, Lithuania, Poland, Russia, and Sweden) to protect the environment of the Baltic Sea (Blenckner et al., 2015; Elmgren et al., 2015; Valman, 2016). The situation under this agreement is close to the non-cooperative scenario depicted in the previous section. A command-and-control management model was adopted that set fixed targets (e.g., a 40\% reduction of nutrient inputs into the sea for all countries). The Baltic Sea Action Plan was signed in 2007 by the same countries (and by the EU) based on an ecosystem approach (Hassler et al., 2013; Valman et al., 2016; Varjopuro et al., 2014); in this approach, a desired ecosystem status must be 
achieved, even if this requires different policies for some countries. This is close to the strong sustainability paradigm depicted in the previous section.

In this section, I will assess whether this governance model (i.e., strong sustainability in a noncooperative scenario) is efficient in terms of welfare and effective in terms of environment use by suggesting specific policies for specific countries, and will investigate whether there are alternative but equivalent sustainability paradigms in terms of welfare or environment use by identifying which specific policies should be implemented to support these paradigms.

\subsection{Data and normalisations}

Some parameters of the model developed in section 3 can be directly estimated. In particular, the proportions of the total current population in each country were based on World Bank world development indicators (http://data.worldbank.org) for 2012 (Table 2). Note that I approximated the relevant populations (i.e., those that are affected by HELCOM) in Germany, Poland, and Russia as 40,20 , and $10 \%$ of the total national population, respectively, since not all of the population lives close enough to the Baltic Sea to be included in the analysis.

Table 2. The dataset used in the Baltic Sea study. Per capita consumption by the future generation $(X F)=8.354$, per capita use of the environment by the future generation $(E F)=1.7$, and utility for the future generation as a

function of the consumption level $(U F)=2.015$. Abbreviations for the current generation in each country: $\alpha$, preference for consumption; $\beta$, the degree of concern for nature; $\gamma$, the degree of concern for future generations; $\theta$, use of the environment per unit consumption; $E$, use of the environment; $p$, proportion of the total population; PPP, purchasing power parity; $U$, utility as a function of the consumption level; $X$, per capita consumption. Min $=$ the smallest value across countries; Gini $=$ Gini inequality index; Average $=$ weighted mean based on the percentage of the total population.

\begin{tabular}{|c|c|c|c|c|c|c|c|c|c|c|c|c|c|}
\hline & 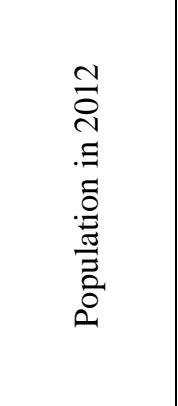 & $p$ & $E$ & 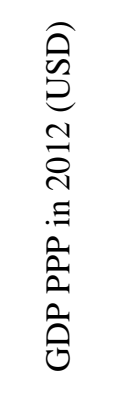 & $\theta$ & 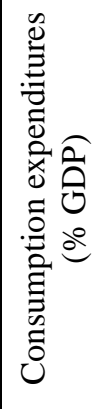 & $X$ & $\alpha$ & 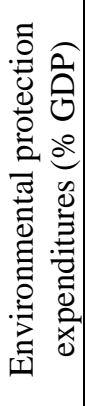 & $\beta$ & 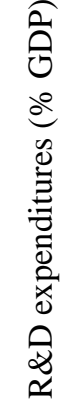 & $\gamma$ & $U$ \\
\hline DNK & $5,591,572$ & 0.08 & 5.5 & 42,869 & 0.13 & 67.60 & 28.979 & 0.33 & 0.60 & 0.01 & 3.00 & 0.02 & 3.070 \\
\hline EST & $1,322,696$ & 0.02 & 6.9 & 25,287 & 0.27 & 60.70 & 15.349 & 0.33 & 1.20 & 0.02 & 2.11 & 0.01 & 2.442 \\
\hline FIN & $5,413,971$ & 0.07 & 5.9 & 39,489 & 0.15 & 71.10 & 28.077 & 0.33 & 0.70 & 0.01 & 3.42 & 0.02 & 3.041 \\
\hline $\mathrm{DEU}$ & $16,085,165$ & 0.22 & 5.3 & 43,035 & 0.12 & 67.80 & 29.178 & 0.33 & 1.10 & 0.01 & 2.87 & 0.02 & 3.050 \\
\hline LVA & $2,034,319$ & 0.03 & 6.3 & 20,482 & 0.31 & 71.10 & 14.563 & 0.33 & 2.90 & 0.04 & 2.34 & 0.02 & 2.332 \\
\hline LTU & $2,987,773$ & 0.04 & 5.8 & 23,722 & 0.24 & 64.60 & 15.325 & 0.33 & 0.70 & 0.01 & 1.92 & 0.01 & 2.464 \\
\hline POL & $15,225,266$ & 0.21 & 4.4 & 22,872 & 0.19 & 71.30 & 16.308 & 0.33 & 0.80 & 0.01 & 0.88 & 0.01 & 2.498 \\
\hline RUS & $14,320,168$ & 0.20 & 5.7 & 23,299 & 0.24 & 58.60 & 13.653 & 0.33 & 0.50 & 0.01 & 1.13 & 0.01 & 2.367 \\
\hline SWE & $9,519,374$ & 0.13 & 7.3 & 43,263 & 0.17 & 65.10 & 28.164 & 0.33 & 0.50 & 0.01 & 3.28 & 0.02 & 3.048 \\
\hline Min & & & 4.400 & & & & 13.653 & & & & & & 2.356 \\
\hline Gini & & & 0.152 & & & & 0.337 & & & & & & 0.122 \\
\hline Average & & & 5.591 & & & & 21.945 & & 0.80 & 0.01 & 2.14 & 0.01 & 2.753 \\
\hline
\end{tabular}

The ecological conditions of the Baltic Sea have been deteriorating for decades due to the impacts of urbanisation, industrialisation, coastal development, intensive agriculture, forestry, and unsustainable fisheries, and closer cooperation between the policy domains or a merger between sectors to reach a more holistic understanding of the Baltic Sea and its management have been advocated (Valman, 2013). Thus, I will use the ecological footprint (i.e., the biologically productive 
area needed to provide everything an individual uses) as the indicator of the ecosystem's status; that is, a lower footprint value represents less pressure on the environment and thus, a more sustainable solution. The per capita sustainable use of the environment of a representative individual for the world based on the current population level requires $E F$ to be at $\eta=1.7$ ha (http://www.footprintnetwork.org): the actual use of the environment in each country $(E)$ is based on data for 2012 (Table 2). Note that an overall indicator that combines some or all of the indicators suggested by the Marine Strategy Framework Directive (Borja et al., 2011) to be applied to a shared environment has not yet been developed. Thus, the ecological footprint provides a useful proxy until a more sophisticated indicator is developed. Similarly, the UN Sustainable Development Solutions Network (http://unsdsn.org) measures sustainability scores in percentages (e.g., the clean water and fish catch status would be $100 \%$ if this activity were totally sustainable), but the values are calculated for each country, not for a shared environment such as the Baltic Sea. The per capita income in each country (i.e., GDP in USD, purchasing power parity), were based on OECD data (http://www.oecd-ilibrary.org) for 2012 (Table 2). These figures let me calculate $\theta$ for each country. Some parameters of the model developed in section 3 can be indirectly estimated. In particular, I estimated the per capita consumption in each country as a percentage of GDP based on OECD data (http://www.oecd-ilibrary.org) for 2012 (Table 2). These figures let me calculate $X_{i}$ for each country. Since the benchmark scenario is characterised by each country attaching the same importance (i.e., the same budget share) to consumption level, environmental preservation, and the welfare of future generations in this analysis, the budget share for consumption represents the parameter with the maximum budget share (i.e., concerns for the environment and future generations are realistically assumed not to be larger than the preference for consumption), with the budget shares for all parameters summing up to 1 . On this basis, I have fixed $\alpha_{i}$ at 0.33 , and have normalised all other parameters with respect to this value (i.e., I multiplied the observed budget shares by 0.33 ). The per capita government expenditures on environmental protection in each country, as a percentage of GDP, based on OECD data (http://www.oecd-ilibrary.org) for 2012 (Table 2), was multiplied by 4, to account for both public and private expenditures as well as for both direct and indirect expenditures. That is, I assumed equal expenditures for each of these four categories of expenditure. These figures let me calculate $\beta_{i}$ for each country. The per capita government expenditures on environmental R\&D in each country as a percentage of GDP, based on OECD data (http://www.oecd-ilibrary.org) for 2012 (Table 2), was multiplied by 2, to account for both public and private expenditures. That is, I assumed equal expenditures for public and private expenditures. These figures let me calculate $\gamma_{i}$ for each country. Note that since data for per capita consumption and per capita expenditures on environmental R\&D as a percentage of GDP were not available for Latvia and Lithuania, I used the average from the largest group of countries to which they belong (i.e., OECD countries for Latvia and EU countries for Lithuania). These values are quite close to values obtained based on agricultural data for both countries (i.e., 2.65\% in Latvia and $1.90 \%$ in Lithuania).

The remaining parameters of the model developed in section 3 require additional assumptions. In particular, the future population was normalised to 1 . This let me compare indicators for representative individuals for the future generation with weighted indicators for representative individuals for the current generation based on the percentage of the total population. The current generation's aversion to inequality for the current generation $(\varepsilon)$ and for future generations $(\zeta)$ were both in the range [0,1], which represents the minimum and maximum possible aversions to inequality. Consumption of imported goods increases welfare where they are consumed, but might increase the use of the environment and thereby reduce welfare in the country where they are produced and then exported. In the present analysis, I assumed that this effect was negligible because net exports as a percentage of GDP are small in all nine Baltic countries, with an average of $2.0 \%$ in 2012, and have a large standard deviation over time (i.e., 3.8\% from 2011 to 2013).

Table 2 also includes the calculated $U_{\text {i }}$ for each country, together with the weighted $E C$ (5.591), XC (21.945), and $U C$ (2.753), based on the percentage of the total population, to depict the current representative individual who will be compared with the future representative individual. 


\subsection{Non-cooperative solutions $(\beta, y)$}

To avoid issues related to recursion (e.g., sustainable consumption in each country depends on the use of the environment and on consumption by all countries), I solved the systems of equations presented in section 3 in two steps. First, I found solutions in terms of a proportional change in $X$ (hereafter, $\Delta$ Mean) to meet condition II, and then found country-specific values of parameters $\beta$ and $\gamma$ which support these solutions while meeting condition I. Second, I searched for a proportional change in the current parameters $\beta$ and $\gamma$ (hereafter, $\Delta$ Mean) to meet condition I, and then found country-specific values in $X$ that support these solutions while meeting condition II. Note that weak inequalities will be solved as if they were equalities in order to maximise the feasibility of the solution.

Table 3. Sustainability solutions in non-cooperative scenarios for strong sustainability (parameter names followed by SS) and de-growth (parameter names followed by DG). Future consumption $(X F)=8.354$, future utility $(U F)=2.015$. Abbreviations: $\beta$, concern for nature; $\gamma$, concern for future generations; $E$, per capita use of the environment; $X$, per capita consumption; $U$, per capita utility. Within the de-growth columns, grey columns refer to results with a change in $\beta$; white columns refer to results with a change in $\gamma$. The $\Delta$ terms represent changes in percentages; the $\Delta$ Mean terms in the $X, \beta$ and $\gamma$ columns represent the proportional change in $X$ required to meet condition II, and the proportional changes in $\beta$ and $\gamma$ required to meet condition I, respectively. Min = the smallest value across countries; Gini = Gini inequality index; Average $=$ weighted mean based on the percentage of the total population.

\begin{tabular}{|c|c|c|c|c|c|c|c|c|c|c|c|c|c|c|}
\hline & $X_{\mathrm{SS}}$ & $E_{\mathrm{SS}}$ & $U_{\mathrm{SS}}$ & $-\Delta U_{\mathrm{SS}}$ & $X_{\mathrm{DG}}$ & $E_{\mathrm{DG}}$ & $\beta_{\mathrm{DG}}$ & $\Delta \beta_{\mathrm{DG}}$ & $U_{\mathrm{DG}}$ & $-\Delta U_{\mathrm{DG}}$ & $\gamma_{\mathrm{DG}}$ & $\Delta \gamma_{\mathrm{DG}}$ & $U_{\mathrm{DG}}$ & $-\Delta U_{\mathrm{DG}}$ \\
\hline DNK & 13.077 & 1.68 & 2.378 & 0.22 & 11.134 & 1.43 & 0.334 & 54.62 & 2.008 & 0.34 & -0.129 & $\mathbf{- 5 . 3 1}$ & 2.019 & 0.34 \\
\hline EST & 6.296 & 1.72 & 1.851 & 0.24 & 5.897 & 1.61 & -0.299 & $\mathbf{- 2 5 . 9 4}$ & 2.102 & 0.14 & 0.172 & 7.16 & 2.015 & 0.18 \\
\hline FIN & 11.333 & 1.69 & 2.274 & 0.25 & 10.787 & 1.61 & 0.312 & 43.54 & 1.935 & 0.36 & -0.114 & $\mathbf{- 4 . 3 3}$ & 2.017 & 0.33 \\
\hline DEU & 14.167 & 1.74 & 2.432 & 0.20 & 11.210 & 1.38 & 0.338 & 29.70 & 2.031 & 0.33 & -0.130 & $\mathbf{- 5 . 5 3}$ & 2.020 & 0.34 \\
\hline LVA & 5.484 & 1.69 & 1.756 & 0.25 & 5.595 & 1.72 & -0.345 & $\mathbf{- 1 2 . 9 1}$ & 2.164 & 0.08 & 0.205 & 7.77 & 2.006 & 0.14 \\
\hline LTU & 7.083 & 1.73 & 1.926 & 0.22 & 5.888 & 1.44 & -0.305 & $\mathbf{- 4 4 . 5 3}$ & 2.033 & 0.17 & 0.171 & 7.88 & 2.018 & 0.18 \\
\hline POL & 8.947 & 1.72 & 2.065 & 0.17 & 6.265 & 1.21 & -0.266 & $\mathbf{- 3 4 . 2 5}$ & 1.938 & 0.22 & 0.142 & 15.12 & 2.021 & 0.19 \\
\hline RUS & 7.083 & 1.73 & 1.918 & 0.19 & 5.246 & 1.28 & -0.433 & $\mathbf{- 8 7 . 5 5}$ & 1.940 & 0.18 & 0.224 & 18.81 & 2.019 & 0.15 \\
\hline SWE & 10.000 & 1.69 & 2.182 & 0.28 & 10.821 & 1.83 & 0.312 & 61.38 & 1.861 & 0.39 & -0.116 & $\mathbf{- 4 . 5 4}$ & 2.017 & 0.34 \\
\hline$\Delta$ Mean & & & & & 0.384 & & 1.5 & & & & 0.9 & & & \\
\hline Min & 5.484 & 1.678 & $\mathbf{1 . 7 5 6}$ & & 5.246 & 1.205 & & & $\mathbf{1 . 8 6 1}$ & & & & $\mathbf{2 . 0 0 6}$ & \\
\hline Gini & 0.354 & $\mathbf{0 . 0 1 5}$ & $\mathbf{0 . 1 2 4}$ & & 0.337 & $\mathbf{0 . 1 4 6}$ & & & $\mathbf{0 . 0 4 9}$ & & & & $\mathbf{0 . 0 0 2}$ & \\
\hline Average & 10.150 & $\mathbf{1 . 7 1 8}$ & 2.154 & $\mathbf{0 . 2 1}$ & 8.431 & $\mathbf{1 . 4 2 0}$ & & & 1.967 & $\mathbf{0 . 2 7}$ & & & 2.019 & $\mathbf{0 . 2 5}$ \\
\hline
\end{tabular}

Tables 3 and 4 show non-cooperative solutions in the alternative sustainability paradigms for strong sustainability versus de-growth and for weak sustainability versus a-growth, respectively.

These results suggest that strong sustainability can achieve sustainability with the smallest welfare burden: 0.21 with strong sustainability $<0.25$ with de-growth and a change in $\gamma=0.25$ with weak sustainability and a change in $\gamma<0.27$ with de-growth and a change in $\beta$. Thus, the adoption of an ecosystem approach by the Baltic Sea Action Plan is efficient in terms of welfare. Next, strong sustainability reduces inter-generational inequalities in terms of $X(23.2 \%), E(0.4 \%)$, and $U$ (15.2\%). These values are calculated as follows: [(sustainable level for current generation unsustainable level for current generation) / unsustainable level for current generation] [(sustainable level for future generation - unsustainable level for current generation) / unsustainable level for current generation]). In contrast, de-growth with a change in $\beta$ increases inter-generational inequalities in terms of $E$ (by $6.7 \%$ ) and $U$ (by 6.1\%), although both de-growth and weak sustainability with a change in $\gamma$ reduce inter-generational inequalities in terms of $X$ (by $0.5 \%$ for de-growth and by $0.3 \%$ for weak sustainability) and $U$ (by $0.5 \%$ for both de-growth and weak sustainability). 
Table 4. Sustainability solutions in non-cooperative scenarios for a-growth (parameter names followed by AG) and weak sustainability (parameter names followed by WS). Future consumption $(X F)=8.354$, future utility $(U F)=2.015$. Abbreviations: $\beta$, concern for nature; $\gamma$, concern for future generations; $E$, per capita use of the environment; $X$, per capita consumption; $U$, per capita utility. Within the weak sustainability columns, grey columns refer to results with a change in $\beta$; white columns refer to results with a change in $\gamma$. The $\Delta$ terms represent changes in percentages; the $\Delta$ Mean terms in the $X, \beta$ and $\gamma$ columns represent the proportional change

in $X$ required to meet condition $I$, and the proportional changes in $\beta$ and $\gamma$ required to meet condition $I$, respectively. Min = the smallest value across countries; Gini $=$ Gini inequality index; Average $=$ weighted mean based on the percentage of the total population.

\begin{tabular}{|c|c|c|c|c|c|c|c|c|c|c|c|c|c|c|}
\hline & $X_{\mathrm{AG}}$ & $E_{\mathrm{AG}}$ & $X_{\mathrm{WS}}$ & $E_{\mathrm{WS}}$ & $\beta_{\mathrm{AG}}$ & $\mathrm{U}_{\mathrm{AG}}$ & $\beta_{\mathrm{WS}}$ & $\Delta \beta_{\mathrm{WS}}$ & $U_{\mathrm{WS}}$ & $-\Delta U_{\mathrm{WS}}$ & $\gamma_{\mathrm{WS}}$ & $\Delta \gamma_{\mathrm{WS}}$ & $U_{\mathrm{WS}}$ & $-\Delta U_{\mathrm{WS}}$ \\
\hline DNK & 13.458 & 1.73 & 11.090 & 1.42 & & & 1.491 & 247.49 & 1.335 & 0.56 & -0.127 & $\mathbf{- 5 . 2 4}$ & 2.019 & 0.34 \\
\hline EST & 7.128 & 1.95 & 5.874 & 1.60 & & & 1.885 & 156.05 & 0.748 & 0.69 & 0.174 & 7.25 & 2.015 & 0.18 \\
\hline FIN & 13.039 & 1.95 & 10.745 & 1.61 & & & 1.491 & 211.94 & 1.107 & 0.63 & -0.112 & $\mathbf{- 4 . 2 7}$ & 2.017 & 0.33 \\
\hline DEU & 13.550 & 1.67 & 11.166 & 1.38 & & & 0.984 & 88.42 & 1.654 & 0.46 & -0.128 & $\mathbf{- 5 . 4 6}$ & 2.020 & 0.34 \\
\hline LVA & 6.763 & 2.08 & 5.573 & 1.71 & & & 1.549 & 52.42 & 0.778 & 0.67 & 0.207 & 7.84 & 2.006 & 0.14 \\
\hline LTU & 7.117 & 1.74 & 5.865 & 1.43 & & & 1.525 & 216.83 & 1.049 & 0.57 & 0.172 & 7.98 & 2.018 & 0.18 \\
\hline POL & 7.573 & 1.46 & 6.241 & 1.20 & & & 0.773 & 95.66 & 1.598 & 0.36 & 0.144 & 15.33 & 2.021 & 0.19 \\
\hline RUS & 6.341 & 1.55 & 5.225 & 1.28 & & & 0.698 & 138.59 & 1.465 & 0.38 & 0.226 & 18.98 & 2.019 & 0.15 \\
\hline SWE & 13.079 & 2.21 & 10.778 & 1.82 & & & 1.077 & 214.44 & 1.177 & 0.61 & -0.114 & $\mathbf{- 4 . 4 9}$ & 2.017 & 0.34 \\
\hline$\Delta$ Mean & $\mathbf{0 . 4 6 4}$ & & $\mathbf{0 . 3 8 3}$ & & $\mathbf{2 2 0 2}$ & & $\mathbf{1 3 9}$ & & & & $\mathbf{1 . 0}$ & & & \\
\hline Min & 6.341 & 1.457 & 5.225 & 1.201 & & & & & 0.748 & & & & $\mathbf{2 . 0 0 6}$ & \\
\hline Gini & 0.337 & 0.146 & 0.337 & $\mathbf{0 . 1 4 6}$ & & & & & 0.291 & & & & $\mathbf{0 . 0 0 2}$ & \\
\hline Average & & & 8.398 & $\mathbf{1 . 4 1 5}$ & & & & & 1.411 & $\mathbf{0 . 4 8}$ & & & 2.019 & $\mathbf{0 . 2 5}$ \\
\hline
\end{tabular}

However, the strong sustainability solution is not Gini-equitable in terms of welfare (i.e., Gini for $U$ $=0.002$ with de-growth and a change in $\gamma=0.002$ with weak sustainability and a change in $\gamma<$ 0.049 with de-growth and a change in $\beta<0.124$ with strong sustainability) nor is it MaxMinequitable in terms of welfare (i.e., MaxMin for $U=2.006$ with de-growth and a change in $\gamma=2.006$ with weak sustainability and a change in $\gamma>1.861$ with de-growth and a change in $\beta>1.756$ with strong sustainability). Next, the strong sustainability solution is not effective in terms of use of the environment (i.e., Average $E=1.718$ with strong sustainability $>1.420$ with de-growth $>1.415$ with weak sustainability).

Note that an average increase in $\beta$ larger than 33 (i.e., $0.33 / 0.01$, the weighted average percentage expenditure on environmental protection in Table 2) is assumed to be unfeasible. Moreover, to avoid under-determination of the numerical system, $U F=U_{i}$ rather than $U F=U C$ is used for cooperative scenarios. Finally, an average increase in $\gamma$ larger than 33 (i.e., 0.33/0.01, the weighted average percentage expenditure on environmental R\&D in Table 2) is assumed to be unfeasible.

In general, in terms of internal consistency, Tables 3 and 4 suggest that weak sustainability is never Kaldor-Hicks efficient and thus is internally inconsistent. A-growth is never feasible. De-growth is never MaxMin-equitable and thus it is internally inconsistent. Strong sustainability is Gini-equitable in terms of use of the environment (i.e., Gini for $E=0.015$ with strong sustainability $<0.146$ with de-growth $=0.146$ with weak sustainability) and so it is internally consistent.

As far consistency with equity approaches, there are no Kaldor-Hicks efficient solutions (i.e., Average $U$ is less than 2.753 for all sustainability solutions). This implies that the utilitarian approach (i.e., Kaldor-Hicks efficient for $U C$ ) is unfeasible. De-growth and a change in $\gamma$ (Gini $=$ 0.002 ), de-growth and a change in $\beta$ (Gini $=0.049$ ), and weak sustainability and a change in $\gamma$ (Gini $=0.002$ ) are Gini-equitable in terms of welfare (i.e., Gini indexes for $U C$ are smaller than 0.122 for all these sustainability solutions). Thus, these paradigms are consistent with an Arneson egalitarian approach (i.e., Gini-equitable for $U C$ ). Strong sustainability, de-growth, and weak sustainability are not Gini-equitable in terms of consumption (i.e., Gini indexes for $X C$ are 0.337 for all these sustainability solutions), whereas strong sustainability (Gini $=0.015)$, de-growth and a change in $\beta$ $($ Gini $=0.146)$, de-growth and a change in $\gamma($ Gini $=0.146)$, and weak sustainability $($ Gini $=0.146)$ are Gini-equitable in terms of use of the environment (i.e., Gini indexes for $E C$ are smaller than 
0.152 for all these sustainability solutions). Thus, these paradigms are consistent with the Dworkin egalitarian approach (i.e., Gini-equitable for $X C$ or Gini-equitable for $E C$ ), but not consistent with the Sen egalitarian approach (i.e., Gini-equitable for $X C$ and Gini-equitable for $E C$ ). There are no MaxMin-equitable solutions (i.e., the MaxMin value for average $U, X$, and $E$ is smaller than 2.356, 13.653, and 4.400, respectively, in all sustainability solutions). This implies that the contractarian approach (i.e., MaxMin-equitable for $U C, X C$, and $E C$ ) is unfeasible.

In terms of environmental policies, Tables 3 and 4 suggest that de-growth requires an average increase by $50 \%$ in expenditures on environmental protection (i.e., $\Delta$ Mean $=1.5$ ) if coupled with a change in responsibility to nature, but only Denmark, Finland, Germany and, Sweden should increase their environmental protection. In contrast, de-growth requires an average decrease by $10 \%$ in expenditures on environmental $\mathrm{R} \& \mathrm{D}$ (i.e., $\Delta$ Mean $=0.9$ ) if coupled with a change in responsibility to future generations, but Estonia, Latvia, Lithuania, Poland, and Russia should increase their environmental $R \& D$. Weak sustainability requires the current average expenditures on environmental $\mathrm{R} \& \mathrm{D}$ (i.e., $\Delta$ Mean $=1.0$ ) if coupled with a change in responsibility to future generations, but Estonia, Latvia, Lithuania, Poland, and Russia should increase their environmental R\&D.

\subsection{Cooperative solutions $(\beta, Y, \varepsilon, \zeta)$}

Table 5 shows a lack of feasible solutions for the a-growth and weak sustainability paradigms in a cooperative scenario, where strong sustainability and de-growth are not analysed for the discussed above definitional and computational reasons, respectively. Thus, the non-cooperative approach adopted by HELCOM is rational.

Table 5. Required value changes in cooperative scenarios for a-growth (parameter names followed by AG) and weak sustainability (parameter names followed by WS). Abbreviations: $\beta$, concern for nature; $\gamma$, concern for future generations; $\varepsilon$, the degree of aversion to intra-generational inequality; $\zeta$, the degree of aversion to intergenerational inequality. The $\Delta$ Mean terms in the $\beta$ and $\gamma$ columns represent the proportional change in $\beta$ and $\gamma$ required to meet condition $I$.

\begin{tabular}{|c|c|c|c|}
\hline Conditions & $\Delta$ Mean $\beta_{\mathrm{AG}}$ & $\Delta$ Mean $\beta_{\mathrm{WS}}$ & $\Delta$ Mean $\gamma_{\mathrm{WS}}$ \\
\hline$\varepsilon=\zeta=0$ & 1998 & 129 & -156 \\
\hline$\varepsilon=1$ and $\zeta=0$ & No solutions & 58 & No solutions \\
\hline$\varepsilon=0$ and $\zeta=1$ & -314 & -119 & 107 \\
\hline
\end{tabular}

Note that a cooperative solution with $\varepsilon=1$ (i.e., welfare is equalised across current generations) is less feasible (i.e., no solutions in 2 out of 3 cases) than a cooperative solution with $\zeta=1$ (i.e., welfare is equalised between current and future generations). In other words, a change in attitude from non-cooperative to cooperative should be achieved by emphasising inter-generational rather than intra-generational inequality aversion.

\subsection{Sensitivity analyses $(\alpha, \theta)$}

Tables 6 and 7 show non-cooperative solutions in the alternative sustainability paradigms for strong sustainability versus de-growth and for weak sustainability versus a-growth, respectively. In both cases, a smaller value is attached to consumption than in Tables 3 and 4 (i.e., all $\alpha_{i}$ are multiplied by $0.75)$.

Comparing Tables 6 and 7 with Tables 3 and 4 suggests that strong sustainability is still feasible, but is unaffected by modified consumption patterns, which is consistent with the theoretical results presented in section 4.3. A-growth is still unfeasible. De-growth coupled with a change in $\beta$ is more feasible (i.e., the average required change in $\beta$ is now 0.7 rather than 1.5) and is less expensive (i.e., the average required change in $U$ is now $20 \%$ rather than 27\%). By contrast, de-growth coupled with a change in $\gamma$ is less feasible (i.e., the average required change in $\gamma$ is now 1.1 rather than 0.9), although it is less expensive (i.e., the average required change in $U$ is now 20\% rather than 25\%). These empirical findings are consistent with the theoretical insights presented in section 4.3. Weak sustainability coupled with a change in $\beta$ is still unfeasible, although the average required change in 
$\beta$ is now 101 rather than 137. In contrast, weak sustainability coupled with a change in $\gamma$ is equally feasible (i.e., the average required change in $\gamma$ is still 0) but is less expensive (i.e., the average required change in $U$ is now $20 \%$ rather than $25 \%$ ). These empirical findings are also consistent with the theoretical insights presented in section 4.3.

Table 6. Sustainability solutions in non-cooperative scenarios for strong sustainability (parameter names followed by SS) and de-growth (parameter names followed by DG). Future per capita consumption $(X F)=8.354$, future utility $(U F)=1.691$. Abbreviations: $\beta$, concern for nature; $\gamma$, concern for future generations; $E$, per capita use of the environment; $X$, per capita consumption; $U$, per capita utility. Within the de-growth columns, grey

columns refer to results with a change in $\beta$; white columns refer to results with a change in $\gamma$. The $\Delta$ terms represent changes in percentages; the $\Delta$ Mean terms in the $X, \beta$ and $\gamma$ columns represent the proportional change

in $X$ required to meet condition II, and the proportional changes in $\beta$ and $\gamma$ required to meet condition $I$, respectively. Min = the smallest value across countries; Gini $=$ Gini inequality index; Average = weighted mean based on the percentage of the total population.

\begin{tabular}{|c|c|c|c|c|c|c|c|c|c|c|c|c|c|c|}
\hline & $X_{\mathrm{SS}}$ & $E_{\mathrm{SS}}$ & $U_{\mathrm{SS}}$ & $-\Delta U_{\mathrm{SS}}$ & $X_{\mathrm{DG}}$ & $E_{\mathrm{DG}}$ & $\beta_{\mathrm{DG}}$ & $\Delta \beta_{\mathrm{DG}}$ & $U_{\mathrm{DG}}$ & $-\Delta U_{\mathrm{DG}}$ & $\gamma_{\mathrm{DG}}$ & $\Delta \gamma_{\mathrm{DG}}$ & $U_{\mathrm{DG}}$ & $-\Delta U_{\mathrm{DG}}$ \\
\hline DNK & 13.077 & 1.68 & 1.914 & 0.175 & 11.134 & 1.43 & -0.003 & 0.250 & 1.847 & 0.204 & -0.128 & $\mathbf{- 5 . 2 7}$ & 1.694 & 0.270 \\
\hline EST & 6.296 & 1.72 & 1.584 & 0.189 & 5.897 & 1.61 & 0.005 & $\mathbf{- 0 . 2 2 4}$ & 1.565 & 0.199 & 0.174 & 7.26 & 1.690 & 0.135 \\
\hline FIN & 11.333 & 1.69 & 1.850 & 0.196 & 10.787 & 1.61 & 0.021 & 0.234 & 1.816 & 0.211 & -0.113 & $\mathbf{- 4 . 2 9}$ & 1.692 & 0.265 \\
\hline DEU & 14.167 & 1.74 & 1.945 & 0.157 & 11.210 & 1.38 & 0.030 & 0.253 & 1.828 & 0.207 & -0.128 & $\mathbf{- 5 . 4 7}$ & 1.694 & 0.266 \\
\hline LVA & 5.484 & 1.69 & 1.519 & 0.192 & 5.595 & 1.72 & 0.000 & $\mathbf{- 0 . 2 5 9}$ & 1.550 & 0.176 & 0.210 & 7.97 & 1.683 & 0.105 \\
\hline LTU & 7.083 & 1.73 & 1.634 & 0.169 & 5.888 & 1.44 & 0.019 & $\mathbf{- 0 . 2 2 9}$ & 1.556 & 0.209 & 0.172 & 7.94 & 1.693 & 0.139 \\
\hline POL & 8.947 & 1.72 & 1.721 & 0.134 & 6.265 & 1.21 & 0.004 & $\mathbf{- 0 . 2 0 0}$ & 1.581 & 0.204 & 0.143 & 15.27 & 1.695 & 0.147 \\
\hline RUS & 7.083 & 1.73 & 1.629 & 0.147 & 5.246 & 1.28 & 0.008 & $\mathbf{- 0 . 3 2 5}$ & 1.513 & 0.208 & 0.225 & 18.88 & 1.694 & 0.113 \\
\hline SWE & 10.000 & 1.69 & 1.794 & 0.222 & 10.821 & 1.83 & -0.018 & 0.234 & 1.855 & 0.196 & -0.115 & $\mathbf{- 4 . 5 2}$ & 1.692 & 0.266 \\
\hline$\Delta$ Mean & & & & & $\mathbf{0 . 6 1 6}$ & & $\mathbf{0 . 7}$ & & & & $\mathbf{1 . 1}$ & & & \\
\hline Min & 5.484 & 1.678 & 1.519 & & 5.246 & 1.205 & & & 1.513 & & & & 1.683 & \\
\hline Gini & 0.354 & 0.015 & 0.094 & & 0.337 & 0.146 & & & 0.090 & & & & 0.002 & \\
\hline Average & 10.150 & 1.718 & 1.775 & 0.165 & 8.431 & 1.420 & & & 1.694 & 0.204 & & & 1.693 & 0.199 \\
\hline
\end{tabular}

Table 7. Sustainability solutions in non-cooperative scenarios for a-growth (parameter names followed by AG) and weak sustainability (parameter names followed by WS). Future per capita consumption $(X F)=8.354$, future utility $(U F)=1.691$. Abbreviations: $\beta$, concern for nature; $\gamma$, concern for future generations; $E$, per capita use of

the environment; $X$, per capita consumption; $U$, per capita utility. Within weak sustainability columns, grey

columns refer to results with a change in $\beta$; white columns refer to results with a change in $\gamma$. The $\Delta$ terms represent changes in percentages; the $\Delta$ Mean terms in the $X, \beta$ and $\gamma$ columns represent the proportional change

in $X$ required to meet condition $I$, and the proportional changes in $\beta$ and $\gamma$ required to meet condition $I$, respectively. Min = the smallest value across countries; Gini $=$ Gini inequality index; Average $=$ weighted mean based on the percentage of the total population.

\begin{tabular}{|c|c|c|c|c|c|c|c|c|c|c|c|c|c|c|}
\hline & $X_{\mathrm{AG}}$ & $E_{\mathrm{AG}}$ & $X_{\mathrm{WS}}$ & $E_{\mathrm{WS}}$ & $\beta_{\mathrm{AG}}$ & $U_{\mathrm{AG}}$ & $\beta_{\mathrm{WS}}$ & $\Delta \beta_{\mathrm{WS}}$ & $U_{\mathrm{WS}}$ & $-\Delta U_{\mathrm{WS}}$ & $\gamma_{\mathrm{WS}}$ & $\Delta \gamma_{\mathrm{WS}}$ & $U_{\mathrm{WS}}$ & $-\Delta U_{\mathrm{WS}}$ \\
\hline DNK & 13.458 & 1.73 & 11.180 & 1.43 & & & 1.102 & 182.73 & 1.241 & 0.465 & -0.130 & $\mathbf{- 5 . 3 3}$ & 1.694 & 0.270 \\
\hline EST & 7.128 & 1.95 & 5.922 & 1.62 & & & 1.392 & 114.97 & 0.805 & 0.588 & 0.172 & 7.17 & 1.691 & 0.135 \\
\hline FIN & 13.039 & 1.95 & 10.832 & 1.62 & & & 1.102 & 156.44 & 1.080 & 0.531 & -0.115 & $\mathbf{- 4 . 3 5}$ & 1.692 & 0.264 \\
\hline DEU & 13.550 & 1.67 & 11.257 & 1.39 & & & 0.729 & 65.27 & 1.457 & 0.369 & -0.130 & $\mathbf{- 5 . 5 3}$ & 1.694 & 0.266 \\
\hline LVA & 6.763 & 2.08 & 5.618 & 1.73 & & & 1.145 & 38.49 & 0.829 & 0.559 & 0.208 & 7.90 & 1.683 & 0.105 \\
\hline LTU & 7.117 & 1.74 & 5.912 & 1.45 & & & 1.127 & 160.04 & 1.035 & 0.474 & 0.170 & 7.85 & 1.693 & 0.139 \\
\hline POL & 7.573 & 1.46 & 6.291 & 1.21 & & & 0.574 & 70.75 & 1.419 & 0.285 & 0.141 & 15.06 & 1.695 & 0.147 \\
\hline RUS & 6.341 & 1.55 & 5.267 & 1.29 & & & 0.518 & 102.67 & 1.331 & 0.303 & 0.223 & 18.72 & 1.694 & 0.113 \\
\hline SWE & 13.079 & 2.21 & 10.866 & 1.83 & & & 0.798 & 158.59 & 1.132 & 0.509 & -0.117 & $\mathbf{- 4 . 5 8}$ & 1.692 & 0.266 \\
\hline$\Delta$ Mean & $\mathbf{0 . 5 3 6}$ & & $\mathbf{0 . 6 1 7}$ & & $\mathbf{1 6 5 2}$ & & $\mathbf{1 0 1}$ & & & & $\mathbf{1 . 0}$ & & & \\
\hline Min & 6.341 & 1.457 & 5.267 & 1.210 & & & & & 0.805 & & & & 1.683 & \\
\hline Gini & 0.337 & 0.146 & 0.337 & 0.146 & & & & & 0.221 & & & & 0.002 & 0.392 \\
\hline Average & 10.191 & 1.717 & 8.466 & 1.426 & & & & & 1.290 & 0.390 & & & 1.694 & 0.199 \\
\hline
\end{tabular}


However, for both de-growth and weak sustainability, all signs of changes in the values do not differ from those in Tables 3 and 4, although the values differ. In other words, similar environmental policies are suggested for the same countries, although with smaller and larger percentage changes for weak sustainability and de-growth, respectively.

Table 8. Required value changes in the cooperative scenarios for a-growth (parameter names followed by AG) and weak sustainability (parameter names followed by WS). Abbreviations: $\beta$, concern for nature; $\gamma$, concern for future generations; $\varepsilon$, the degree of aversion to intra-generational inequality; $\zeta$, the degree of aversion to intergenerational inequality. The $\Delta$ Mean terms in the $\beta$ and $\gamma$ columns represent the proportional change in $\beta$ and $\gamma$ required to meet condition $I$.

\begin{tabular}{|c|c|c|c|}
\hline Conditions & $\Delta$ Mean $\beta_{\mathrm{AG}}$ & $\Delta$ Mean $\beta_{\mathrm{WS}}$ & $\Delta$ Mean $\gamma_{\mathrm{WS}}$ \\
\hline$\varepsilon=\zeta=0$ & 1498 & 94 & -138 \\
\hline$\varepsilon=1$ and $\zeta=0$ & No solutions & 37 & no solutions \\
\hline$\varepsilon=0$ and $\zeta=1$ & -48 & -300 & 126 \\
\hline
\end{tabular}

Table 8 highlights the lack of feasible solutions for the a-growth and weak sustainability paradigms in a cooperative scenario (i.e., all proportional changes in $\beta$ and $\gamma$ are larger than 33). Thus, the noncooperative approach adopted by HELCOM would be rational in this alternative context too.

Tables 9 and 10 show non-cooperative solutions in the alternative sustainability paradigms for strong sustainability versus de-growth and for weak sustainability versus a-growth, respectively. In both cases, a smaller value is attached to use of the environment per unit consumption than in Tables 3 and 4 (i.e., all $\theta_{i}$ are multiplied by 0.75 ).

Table 9. Sustainability solutions in non-cooperative scenarios for strong sustainability (parameter names followed by SS) and de-growth (parameter names followed by DG). Future per capita consumption $(X F)=$ 11.138, future utility $(U F)=2.215$. Abbreviations: $\beta$, concern for nature; $\gamma$, concern for future generations; $E$, per capita use of the environment; $X$, per capita consumption; $U$, per capita utility. Within the de-growth columns, grey columns refer to results with a change in $\beta$; white columns refer to results with a change in $\gamma$. The

$\Delta$ terms represent changes in percentages; the $\Delta$ Mean terms in the $X, \beta$, and $\gamma$ columns represent the proportional change in $X$ required to meet condition II, and the proportional changes in $\beta$ and $\gamma$ required to meet condition $I$, respectively. Min = the smallest value across countries; Gini = Gini inequality index; Average = weighted mean based on the percentage of the total population.

\begin{tabular}{|c|c|c|c|c|c|c|c|c|c|c|c|c|c|c|}
\hline & $X_{\mathrm{SS}}$ & $E \mathrm{Ss}$ & $U_{\mathrm{SS}}$ & $-\Delta U_{\mathrm{SS}}$ & $X_{\mathrm{DG}}$ & $E_{\mathrm{DG}}$ & $\beta_{\mathrm{DG}}$ & $\Delta \beta_{\mathrm{DG}}$ & $U_{\mathrm{DG}}$ & $-\Delta U_{\mathrm{DG}}$ & $\gamma_{\mathrm{DG}}$ & $\Delta \gamma_{\mathrm{DG}}$ & $U_{\mathrm{DG}}$ & $-\Delta U_{\mathrm{DG}}$ \\
\hline DNK & 17.436 & 1.68 & 2.622 & 0.152 & 14.848 & 1.43 & 0.342 & 56.01 & 2.208 & 0.286 & -0.114 & $\mathbf{- 4 . 7 9}$ & 2.220 & 0.282 \\
\hline EST & 8.395 & 1.72 & 2.039 & 0.175 & 7.864 & 1.61 & -0.293 & $\mathbf{- 2 5 . 4 5}$ & 2.309 & 0.065 & 0.152 & 6.19 & 2.216 & 0.103 \\
\hline FIN & 15.111 & 1.69 & 2.508 & 0.181 & 14.386 & 1.61 & 0.321 & 44.90 & 2.125 & 0.307 & -0.100 & $\mathbf{- 3 . 9 3}$ & 2.218 & 0.276 \\
\hline DEU & 18.889 & 1.74 & 2.682 & 0.130 & 14.950 & 1.38 & 0.346 & 30.42 & 2.234 & 0.275 & -0.114 & $\mathbf{- 4 . 9 9}$ & 2.221 & 0.279 \\
\hline LVA & 7.312 & 1.69 & 1.935 & 0.187 & 7.462 & 1.72 & -0.339 & $\mathbf{- 1 2 . 6 9}$ & 2.377 & 0.001 & 0.181 & 6.73 & 2.206 & 0.073 \\
\hline LTU & 9.444 & 1.73 & 2.122 & 0.145 & 7.852 & 1.44 & -0.299 & $\mathbf{- 4 3 . 7 7}$ & 2.235 & 0.099 & 0.150 & 6.83 & 2.219 & 0.106 \\
\hline POL & 11.930 & 1.72 & 2.272 & 0.096 & 8.356 & 1.21 & -0.264 & $\mathbf{- 3 3 . 9 4}$ & 2.132 & 0.152 & 0.125 & 13.20 & 2.222 & 0.116 \\
\hline RUS & 9.444 & 1.73 & 2.111 & 0.113 & 6.996 & 1.28 & -0.430 & $\mathbf{- 8 6 . 9 2}$ & 2.134 & 0.103 & 0.197 & 16.45 & 2.220 & 0.067 \\
\hline SWE & 13.333 & 1.69 & 2.407 & 0.216 & 14.430 & 1.83 & 0.321 & 63.21 & 2.041 & 0.335 & -0.102 & $\mathbf{- 4 . 1 2}$ & 2.218 & 0.277 \\
\hline$\Delta$ Mean & & & & & $\mathbf{0 . 6 1 6}$ & & $\mathbf{2 . 2}$ & & & & $\mathbf{0 . 8}$ & & & \\
\hline Min & 7.312 & 1.678 & 1.935 & & 6.996 & 1.206 & & & 2.041 & & & & 2.206 & \\
\hline Gini & 0.354 & 0.015 & 0.125 & & 0.337 & 0.146 & & & 0.049 & & & & 0.002 & \\
\hline Average & 13.533 & 1.718 & 2.374 & 0.139 & 11.244 & 1.420 & & & 2.163 & 0.207 & & & 2.220 & 0.187 \\
\hline
\end{tabular}

Comparing Tables 9 and 10 with Tables 3 and 4 suggests that strong sustainability is still feasible, but is less expensive (i.e., the average required change in $U$ is now $14 \%$ rather than $21 \%$ ), which is consistent with the theoretical insights presented in section 4.3. A-growth is still unfeasible. Degrowth coupled with a change in $\beta$ is less feasible (i.e., the average required change in $\beta$ is now 2.2 rather than 1.5) but is also less expensive (i.e., the average required change in $U$ is now $20 \%$ rather than 27\%). In contrast, de-growth coupled with a change in $\gamma$ is more feasible (i.e., the average required change in $\gamma$ is now 0.8 rather than 0.9 ) and less expensive (i.e., the average required change in $U$ is now $19 \%$ rather than 25\%). These empirical findings are consistent with the theoretical 
insights presented in section 4.3. Weak sustainability coupled with a change in $\beta$ is still unfeasible, although the average required change in $\beta$ is now 141 rather than 137. In contrast, weak sustainability coupled with a change in $\gamma$ is equally feasible (i.e., the average required change in $\gamma$ is still 0) but is less expensive (i.e., the average required change in $U$ is now 19\% rather than 25\%). These empirical findings are consistent with the theoretical insights presented in section 4.3.

Table 10. Sustainability solutions in non-cooperative scenarios for a-growth (parameter names followed by AG) and weak sustainability (parameter names followed by WS). Future per capita consumption $(X F)=11.138$, future utility $(U F)=2.215$. Abbreviations: $\beta$, concern for nature; $\gamma$, concern for future generations; $E$, per capita use of the environment; $X$, per capita consumption; $U$, per capita utility. Within the weak sustainability columns, grey columns refer to results with a change in $\beta$; white columns refer to results with a change in $\gamma$. The $\Delta$ terms represent changes in percentages; the $\Delta$ Mean terms in the $X$, $\beta$, and $\gamma$ columns represent the proportional change

in $X$ required to meet condition II, and the proportional changes in $\beta$ and $\gamma$ required to meet condition $I$, respectively. Min $=$ the smallest value across countries; Gini $=$ Gini inequality index; Average $=$ weighted mean based on the percentage of the total population.

\begin{tabular}{|c|c|c|c|c|c|c|c|c|c|c|c|c|c|c|}
\hline & $X_{\mathrm{AG}}$ & $E_{\mathrm{AG}}$ & $X_{\mathrm{WS}}$ & $E_{\mathrm{WS}}$ & $\beta_{\mathrm{AG}}$ & $U_{\mathrm{AG}}$ & $\beta_{\mathrm{WS}}$ & $\Delta \beta_{\mathrm{WS}}$ & $U_{\mathrm{WS}}$ & $-\Delta U_{\mathrm{WS}}$ & $\gamma_{\mathrm{WS}}$ & $\Delta \gamma_{\mathrm{WS}}$ & $U_{\mathrm{WS}}$ & $-\Delta U_{\mathrm{WS}}$ \\
\hline DNK & 17.945 & 1.73 & 14.691 & 1.41 & & & 1.514 & 251.34 & 1.472 & 0.524 & -0.109 & $\mathbf{- 4 . 6 5}$ & 2.220 & 0.282 \\
\hline EST & 9.505 & 1.95 & 7.781 & 1.59 & & & 1.913 & 158.44 & 0.822 & 0.667 & 0.156 & 6.39 & 2.216 & 0.103 \\
\hline FIN & 17.386 & 1.95 & 14.234 & 1.59 & & & 1.514 & 215.34 & 1.217 & 0.603 & -0.096 & $\mathbf{- 3 . 8 1}$ & 2.218 & 0.276 \\
\hline DEU & 18.068 & 1.67 & 14.792 & 1.37 & & & 0.997 & 89.68 & 1.823 & 0.408 & -0.110 & $\mathbf{- 4 . 8 4}$ & 2.221 & 0.279 \\
\hline LVA & 9.018 & 2.08 & 7.383 & 1.70 & & & 1.572 & 53.21 & 0.853 & 0.642 & 0.185 & 6.90 & 2.206 & 0.073 \\
\hline LTU & 9.490 & 1.74 & 7.769 & 1.42 & & & 1.547 & 219.95 & 1.155 & 0.534 & 0.155 & 7.05 & 2.219 & 0.106 \\
\hline POL & 10.098 & 1.46 & 8.267 & 1.19 & & & 0.781 & 96.65 & 1.762 & 0.299 & 0.129 & 13.69 & 2.222 & 0.116 \\
\hline RUS & 8.455 & 1.55 & 6.922 & 1.27 & & & 0.705 & 140.01 & 1.614 & 0.322 & 0.202 & 16.84 & 2.220 & 0.067 \\
\hline SWE & 17.440 & 2.21 & 14.278 & 1.81 & & & 1.093 & 217.66 & 1.293 & 0.579 & -0.098 & $\mathbf{- 3 . 9 9}$ & 2.218 & 0.277 \\
\hline$\Delta$ Mean & $\mathbf{0 . 5 3 6}$ & & $\mathbf{0 . 6 1 7}$ & & & & $\mathbf{1 4 1}$ & & & & $\mathbf{1 . 0}$ & & & \\
\hline Min & 8.455 & 1.457 & 6.922 & 1.193 & & & & & 0.822 & & & & 2.206 & \\
\hline Gini & 0.337 & 0.146 & 0.337 & 0.146 & & & & & 0.292 & & & & 0.002 & \\
\hline Average & 13.589 & 1.717 & 11.125 & 1.405 & & & & & 1.554 & 0.430 & & & 2.220 & 0.187 \\
\hline
\end{tabular}

However, for both de-growth and weak sustainability, all signs for the changes in values do not differ from those in Tables 3 and 4, although the values are different. In other words, similar environmental policies are suggested for the same countries, although with smaller and larger percentage changes for weak sustainability and de-growth, respectively.

Table 11. Required value changes in the cooperative scenarios for a-growth (parameter names followed by AG) and weak sustainability (parameter names followed by WS). Abbreviations: $\beta$, concern for nature; $\gamma$, concern for future generations; $\varepsilon$, the degree of aversion to intra-generational inequality; $\zeta$, the degree of aversion to intergenerational inequality. The $\Delta$ Mean terms in $\beta$ and $\gamma$ columns represent the proportional change in $\beta$ and $\gamma$ required to meet condition $I$.

\begin{tabular}{|c|c|c|c|}
\hline Conditions & $\Delta$ Mean $\beta_{\mathrm{AG}}$ & $\Delta$ Mean $\beta_{\mathrm{WS}}$ & $\Delta$ Mean $\gamma_{\mathrm{WS}}$ \\
\hline$\varepsilon=\zeta=0$ & 2664 & 131 & -137 \\
\hline$\varepsilon=1$ and $\zeta=0$ & No solutions & 71 & No solutions \\
\hline$\varepsilon=0$ and $\zeta=1$ & -343 & -360 & 103 \\
\hline
\end{tabular}

Table 11 highlights the lack of feasible solutions for the a-growth and weak sustainability paradigms in a cooperative scenario (i.e., all proportional changes in $\beta$ and $\gamma$ are larger than 33). Thus, the non-cooperative approach adopted by HELCOM would be rational in this alternative context too.

\section{Discussion}

Based on the Baltic Sea case study, several insights were gained about the sustainability paradigms. Cooperative solutions were never feasible. Among the non-cooperative solutions, strong sustainability is relatively efficient, since it requires the smallest reduction in welfare; it is also 
internally consistent, since it is Gini-equitable in terms of environment use. In addition, it minimises the inter-generational inequality in $X, E$, and $U$, and is consistent with the Dworkin egalitarian approach, since it is not Gini-equitable for $X$, but it is Gini-equitable for $E$. A-growth was never feasible. De-growth can be supported either by an average change in the concern for the environment (i.e., an increase in environmental protection) or by an average increase in the concern for future generations (i.e., an increase in environmental R\&D), although the latter is less expensive than the former. De-growth with a change in the concern for future generations minimises the intragenerational inequality in $U$. De-growth is consistent with the Arneson and Dworkin egalitarian approaches, since it is Gini-equitable for $U$ and $E$. Weak sustainability must be supported by a redistribution of the concern for future generations (i.e., a redistribution among countries of expenditures on environmental $R \& D$ ) at the current average value. Weak sustainability is consistent with the Arneson egalitarian approach, since it is Gini-equitable for $U$. Weak sustainability minimises the intra-generational inequality in $U$, and is effective for $E$, since it minimises the use of the environment.

Thus, the ecosystem approach (i.e., here depicted as strong sustainability) that is currently adopted by HELCOM with a non-cooperative approach (i.e., here, represented as a Nash equilibrium) is relatively efficient in terms of welfare, is internally consistent, and is also consistent with the Dworkin egalitarian approach, but it is not effective in terms of its use of the environment.

The main operational good news (i.e., what is lost if strong sustainability is not adopted) from this study is:

1. Different feasible sustainability paradigms (i.e., weak sustainability and de-growth) support the same policies: the more developed countries (Denmark, Finland, Germany, and Sweden) should invest in environmental protection, whereas the less developed countries (Estonia, Latvia, Lithuania, Poland, and Russia) should invest in R\&D.

2. Different feasible sustainability paradigms (i.e., weak sustainability and de-growth) require similar reductions in welfare to achieve sustainability (i.e., within a range of $25 \%$ to $27 \%$ ), although these are larger than those required by strong sustainability (i.e., 21\%)

3. For all feasible sustainability paradigms, the sustainability burden on the more developed countries (Denmark, Finland, Germany, and Sweden) is proportionally larger than that on the less developed countries (Estonia, Latvia, Lithuania, Poland, and Russia).

4. For all feasible sustainability paradigms, improved environmental technology will increase the welfare of current generations in the less developed countries compared with the status quo, although strong sustainability is the most efficient paradigm (i.e., $U C$ is 2.374 with strong sustainability $>2.163$ with de-growth and a change in $\beta>2.220$ with de-growth and a change in $\gamma=2.220$ with weak sustainability and a change in $\gamma$ ).

Note that the discrimination of countries into two groups according to the policies to be adopted seems to be realistic; this result could therefore be taken as a preliminary validation of the model.

The main operational bad news (i.e., what is gained if strong sustainability is not adopted) from this study is:

1. Alternative feasible sustainability paradigms (i.e., weak sustainability and de-growth) could improve the environmental status to a greater extent than strong sustainability. However, this will require a change of environmental awareness (Tynkkynen et al., 2014), which in turn will require closer involvement of stakeholders and the public (Tynkkynen, 2013) as well as a larger stakeholder involvement, willingness, and capacity to cooperate (Hendriksen et al., 2014).

2. Alternative feasible sustainability paradigms (i.e., weak sustainability and de-growth) could reduce the intra-generational inequality in welfare with respect to strong sustainability. However, this will require a change of environmental perception (Lundberg, 2013), which in turn will require a larger stakeholder capacity, willingness, and commitment to transition to a more sustainable society (Leal Filho et al., 2016) as well as a tighter agreement among the stakeholders on participation, legitimacy, and top-down vs. multi-stakeholder approaches to governance (Hassler, 2016) 
Note that I assumed a one-to-one relationship between changes in environmental policies (e.g., an increase in expenditures for environmental protection or R\&D) and changes in environmental values (e.g., an increase in concern for nature and future generations) because governments in democratic countries would have difficulty in significantly increasing these expenditures from the current tiny levels (i.e., an average of 0.80 and $2.14 \%$ of GDP for environmental protection and $\mathrm{R} \& \mathrm{D}$, respectively) unless these changes are supported by the general population.

Weaknesses of the present study include:

- It does not discuss the implementation of the governance structures needed to efficiently and legitimately implement ecosystem-based marine management at a regional level (Hegland et al., 2015). However, most operational conditions that would favour sustainability have been identified (e.g., an increase in the concern about future generations should be preferred to an increase in the duty to nature; a non-cooperative attitude should be preferred to a cooperative attitude).

- It does not discuss the implementation of strategies and practices to address and cope with uncertainty in complex socio-ecological systems within effective assessment and management frameworks (Udovyk and Gilek, 2013). However, most operational conditions that would favour reliable sustainability have been identified (e.g., an increase in the duty to nature should be preferred to an increase in the concern about future generations; a noncooperative attitude should be preferred to a cooperative attitude).

Strengths of the present study include:

- It accounts for the possibility of environmental free-riding (i.e., some individuals pay for the consequences of environmental use by other individuals).

- The framework combines sustainability paradigms and equity approaches to find an operational route towards sustainability.

- It accounts for the possibility of context changes such as modified consumption and improved technology.

- The framework relates value changes with environmental policies to find a democratic route towards sustainability.

Note that neither a top-down nor a bottom-up approach is suggested to achieve suitable changes in environmental values; instead, the most important features linking these approaches to sustainability paradigms and equity or efficiency approaches are identified.

\section{Conclusions}

Environmental production policies (e.g., taxes or standards) turn out to be insufficient to achieve sustainability in general, particularly if a shared environment is involved. A shift to or a combination with environmental demand policies (e.g., environmental protection based on a sense of responsibility to nature $\beta$; environmental $R \& D$ based on a sense of responsibility to future generations $\gamma$ ) is advocated. However, alternative sustainability paradigms support alternative demand policies (e.g., weak sustainability and a-growth support changes in $\gamma$; de-growth supports changes in $\beta$ ). Moreover, some paradigms are more flexible than others (e.g., strong sustainability disregards both $\beta$ and $\gamma$ as well as non-cooperative and cooperative scenarios). Finally, different sustainability paradigms advocated different context changes (e.g., de-growth supports changes in consumption pattern $\alpha$; weak sustainability and a-growth support changes in environmental technology $\theta$ ).

The methodology developed in this paper suggests demand policies for a shared environment in alternative scenarios and contexts by comparing sustainability paradigms in terms of their effectiveness and stability. Note that suggestions for the global environment might be different, since a sense of responsibility to the least-advantaged current generations could become significant in that context.

Three main theoretical insights were obtained in this study. First, a non-cooperative attitude is more effective whenever one or more countries exhibit a large concern for the environment. Second, the 
perspective of a single individual (i.e., the focus is on individual sustainability), as assumed by strong sustainability, and the perspective of a representative individual (i.e., the focus is on overall sustainability), as assumed by weak sustainability, a-growth, and de-growth, lead to sustainability at similar levels of per capita consumption and use of the environment. Third, if countries are relatively similar with respect to their senses of responsibility to nature and to future generations, a cooperative attitude should be coupled with a concern for future generations $(\zeta=1)$ rather than for current generations $(\varepsilon=1)$.

The main theoretical bad news from this study is that the contextual stability is larger in noncooperative scenarios if weak sustainability or a-growth are adopted, whereas it is larger in a cooperative scenario if de-growth is adopted; in other words, the stability depends on the adopted sustainability paradigm. In any case, stability is larger for a homogeneous group of countries $\left(p_{i} \beta_{i} \approx\right.$ $p_{j} \beta_{j}$ and $\left.p_{i} \gamma_{i} \approx p_{j} \gamma_{j}\right)$.

The main theoretical good news from this study is that the relative effectiveness is larger in noncooperative scenarios for all feasible sustainability paradigms (i.e., weak sustainability, de-growth, and strong sustainability). The case with high inter-generational inequality aversion $(\zeta=1)$ is more effective than the case with high intra-generational inequality aversion $(\varepsilon=1)$ within the cooperative scenarios; in other words, the effectiveness does not depend on the adopted sustainability paradigm. However, effectiveness is smaller for a homogeneous group of countries $\left(p_{i}\right.$ $\beta_{i} \approx p_{j} \beta_{j}$ and $p_{i} \gamma_{i} \approx p_{j} \gamma_{j}$.

Three main developments from this paper seem to be particularly promising. First, it should be possible to apply the model at a sectoral level, with related indicators chosen for pollution production or resource use. Second, it should be possible to develop the current one-shot model to produce a dynamic model, which would allow an investigation of issues related to overlapping generations. Third, it should be possible to apply the model at a global level, with appropriate indicators for pollution production or resource use.

\section{Appendix A}

$\alpha_{\mathrm{F}}$ : the future preference for consumption

$\alpha_{i}$ : the current preference for consumption in country $i$

$\beta_{i}$ : the degree of current concern for nature in country $i$

$\gamma_{i}$ : the degree of current concern for future generations in country $i$

$\delta_{i}$ : the degree of current concern for less-developed current generations in country $i$

$\varepsilon$ : the degree of aversion to intra-generational inequality

$\zeta$ : the degree of aversion to inter-generational inequality

$\eta$ : per capita equilibrium use of the environment consistent with the current relevant population

$\theta_{i}$ : the current use of the environment for each consumption unit for the country $i$

$\theta_{\mathrm{F}}$ : the use of the environment for each consumption unit for the future generation

$E C$ : weighted per capita use of the environment by the current generation

$E F$ : per capita use of the environment by the future generation

$E_{i}$ : per capita use of the environment by the current generation in country $i$

$p_{i}$ : proportion of the total population in country $i$

$U$ : overall utility as a function of consumption

$U C$ : weighted utility for the current generation as a function of consumption

$U F$ : utility for the future generation as a function of consumption

$U_{i}$ : utility for the current generation in country $i$ as a function of consumption

$W$ : overall welfare as a function of environment use

$W C$ : welfare of the current generation as a function of environment use

$X C$ : weighted per capita consumption by the current generation

$X F$ : per capita consumption by the future generation

$X_{i}$ : per capita consumption in country $i$ 


\section{Appendix B}

In the case of $n$ countries at different development levels, and which share an environment, the model becomes:

$$
\begin{gathered}
U F=X F^{\alpha \mathrm{F}} \text { with } \alpha_{\mathrm{F}}=\frac{1}{n} \sum_{i}^{n} \alpha_{i} \text { and } X F=\eta / \theta_{\mathrm{F}} \text { with } \theta_{\mathrm{F}}=\frac{1}{n} \sum_{i}^{n} \theta_{i} \\
U_{i}=X_{i}^{\alpha i}\left(\sum p_{i} E_{i}\right)^{-\beta i} U F^{\gamma i}\left(\sum p_{j} U_{j}\right)^{\delta i} \\
U C=\left[\left(\sum p_{i} U_{i}\right)^{1-\varepsilon}\right]^{1 /(1-\varepsilon)} \\
U=\left[U C^{1-\zeta}+U F^{1-\zeta}\right]^{1 /(1-\zeta)} \\
E C=\left[\left(\sum p_{i} E_{i}\right)^{1-\varepsilon}\right]^{1 /(1-\varepsilon)} \\
E=\left[E C^{1-\zeta}+E F^{1-\zeta}\right]^{1 /(1-\zeta)}
\end{gathered}
$$

Where $\delta_{\mathrm{i}}$ represents the degree of current concern for less developed current generations in country $i$ and $i$ refers to a sum that includes all $n$ countries, whereas $j$ refers to a sum that excludes country $i$.

\section{References}

Arneson, R.J. (1989) Equality and equal opportunity for welfare, Philosophical Studies 56: 77-93

Asheim, G.B., Mitra, T, Tungodden, B. (2012) Sustainable recursive social welfare functions, Economic Theory 49: 267-292

Aznar-Marquez, J., Ruiz-Tamarit, J.R. (2016) Environmental pollution, sustained growth, and sufficient conditions for sustainable development, Economic Modelling 54: 439-449

Blenckner, T. et al. (2015) Past and future challenges in managing European seas, Ecology and Society 20: 40

Borja, A. et al. (2011) Implementation of the European Marine Strategy Framework Directive: a methodological approach for the assessment of environmental status, from the Basque Country (Bay of Biscay), Marine Pollution Bulletin 62: 889-904

Caselles, A. (2013) An application of fuzzy cognitive maps to improve well-being, sustainability and the globalization process, Systems Research and Behavioural Science 30: 646-660

Cowell, F.A. (1995) Measuring inequality, LSE handbooks in Economics Series, II edition, London: Prentice Hall

Dworkin, R. (1981) What is equality? Part 2: Equality of resources, Philosophy and Public Affairs 10: 283-345

Elmgren, R., Blenckner, T., Andersson, A. (2015) Baltic Sea Management: successes and failures, Ambio 44: 335-344

Golub, A., Mahoney, M., Harlow, J. (2013) Sustainability and intergenerational equity: do past injustices matter? Sustainability Science 8: 269-277

Gosseries, A. (2008) On future generations' future rights, Journal of Political Philosophy 16: 446474

Habib, A. (2013) Sharing the Earth: sustainability and the currency of inter-generational environmental justice, Environmental Values 22: 751-764

Harsanyi, J.C. (1982) Morality and the theory of rational behaviour, in Sen, A., Williams, B., (eds.) Utilitarianism and beyond, Cambridge: Cambridge University Press, pp. 39-62

Hassler, B. (2016) Transnational environmental collective action facing implementation constraints - the case of nutrient leakage in the Baltic Sea Action Plan, Journal of Environmental Policy and Planning 7: 1-15

Hassler, B. Bostrom, M., Gronholm, S. (2013) Towards an ecosystem approach to management in regional marine governance? The Baltic Sea context, Journal of Environmental Policy and Planning 15: 225-245 
Hegland, T.J., Raakjaer, J., van Tatenhove, J. (2015) Implementing ecosystem-based marine management as a process of regionalisation: some lessons from the Baltic Sea, Ocean and Coastal Management 117: 14-22

Hendriksen, A. et al. (2014) Fishing for opinions: stakeholder views on MSFD implementation in European Seas, Marine Policy 50: 353-363

Jain, P.; Jain, P. (2013) Sustainability assessment index: a strong sustainability approach to measure sustainable human development, International Journal of Sustainable Development and World Ecology 20: 116-122

Kallis, G. (2011) In defence of de-growth, Ecological Economics 70: 873-880

Kallis, G.; Kerschner, C.; Martinez-Alier, J. (2012) The economics of de-growth, Ecological Economics 84: 172-180

Kershnar, S., Purves, D. (2016) A new argument for the irrelevance of equality for intrinsic value, Philosophia (United States) 44: 1-21

Kopnina, H. (2016) The victims of unsustainability: a challenge to sustainable development goals, International Journal of Sustainable Development and World Ecology 23: 113-121

Koukouzelis, K. (2012) Sustainable development, liberty, and global social justice, Public Reason 4: $165-181$

Lauwers, L. (2012) Intergenerational equity, efficiency, and constructability, Economic Theory 49: 227-242

Leal Filho, W. et al. (2016) The role of governance in realising the transition towards sustainable societies, Journal of Cleaner Production 113: 755-766

Lomasky, L. (1987) Persons, Rights, and the Moral Community, New York: Oxford University Press

Lundberg, C. (2013) Eutrophication, risk management and sustainability. The perception of different stakeholders in the northern Baltic Sea, Marine Pollution Bulletin 66: 143-150

Nozick, R. (1974) Anarchy, State, and Utopia, New York: Basic Books

Pedersen, K.P. (2015) Religious ethics and the environment: a review essay, Journal of Religious Ethics 43: 558-585

Rawls, J. (1971) A Theory of Justice, Cambridge: Harvard University Press

Saniotis, A. (2012) Muslims and ecology: fostering Islamic environmental ethics, Contemporary Islam 6: 155-171

Schlör, H.; Fischer, W.; Hake, J.F. (2015) The system boundaries of sustainability, Journal of Cleaner Production 88: 52-60

Sen, A.K. (1993) Capability and well-being, in Nussbaum, M. C., Sen, A. K. (eds.), The Quality of Life, Oxford: Clarendon Press

Tynkkynen, N. (2013) The challenge of environmental governance in the network society: the case of the Baltic Sea, Environmental Policy and Governance 23: 395-406

Tynkkynen, N. et al. (2014) The governance of the mitigation of the Baltic Sea eutrophication: exploring the challenges of the formal governing system, Ambio 43: 105-114

Udovyk, O., Gilek, M. (2013) Coping with uncertainties in science-based advice informing environmental management of the Baltic Sea, Environmental Science and Policy 29: 12-23

Valman, M. (2013) Institutional stability and change in the Baltic Sea: 30 years of issues, crises and solutions, Marine Policy 38: 54-64

Valman, M. (2016) Beliefs and behaviour in international policy making: explanations to longitudinal changes in the governance of the Baltic Sea, Maritime Studies 15: 1-16

Valman, M. et al. (2016) Organizational responsiveness: the case of unfolding crises and problem detection within HELCOM, Marine Policy 70: 49-57

Van den Bergh, J.C.J.M. (2010) Externality or sustainability economics? Ecological Economics 69: 2047-2052

Van den Bergh, J.C.J.M. (2011) Environment versus growth - a criticism of "de-growth" and a plea for “a-growth", Ecological Economics 70: 881-890 
Van der Werff, E., Steg, L., Keizer, K. (2013) It is a moral issue: the relationship between selfidentity, obligation-based intrinsic motivation and pro-environmental behaviour, Global Environmental Change 23: 1258-1265

Varjopuro, R. et al. (2014) Coping with persistent environmental problems: systemic delays in reducing eutrophication of the Baltic Sea, Ecology and Society 19: 48

Zagonari, F. (2015) Technology improvements and value changes for sustainable happiness: a cross-development analytical model, Sustainability Science 10: 687-698

Zagonari, F. (2016) Four sustainability paradigms for environmental management: a methodological analysis and an empirical study based on 30 Italian industries, Sustainability (Switzerland) 8: 504-537 


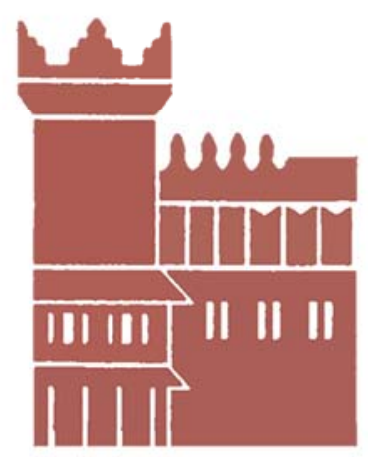

Alma Mater Studiorum - Università di Bologna DEPARTMENT OF ECONOMICS

Strada Maggiore 45

40125 Bologna - Italy

Tel. +39051 2092604

Fax +390512092664

http://www.dse.unibo.it 